\title{
Article
}

\section{An experimental and numerical model for the release of acetone from decomposing EVA containing aluminium, magnesium or calcium hydroxide fire retardants}

Hewitt, Fiona, Rhebat, Diana Eid, Witkowski, Artur and Hull, T Richard

Available at http://clok.uclan.ac.uk/16622/

Hewitt, Fiona, Rhebat, Diana Eid, Witkowski, Artur ORCID: 0000-0002-00057520 and Hull, T Richard ORCID: 0000-0002-7970-4208 (2016) An experimental and numerical model for the release of acetone from decomposing EVA containing aluminium, magnesium or calcium hydroxide fire retardants. Polymer Degradation and Stability, 127 . pp. 65-78. ISSN 01413910

It is advisable to refer to the publisher's version if you intend to cite from the work. http://dx.doi.org/10.1016/j. polymdegradstab.2016.01.007

For more information about UCLan's research in this area go to http://www.uclan.ac.uk/researchgroups/ and search for <name of research Group>.

For information about Research generally at UCLan please go to http://www.uclan.ac.uk/research/

All outputs in CLoK are protected by Intellectual Property Rights law, including Copyright law. Copyright, IPR and Moral Rights for the works on this site are retained by the individual authors and/or other copyright owners. Terms and conditions for use of this material are defined in the policies page. 


\title{
An experimental and numerical model for the release of acetone from decomposing EVA containing aluminium, magnesium or calcium hydroxide fire retardants
}

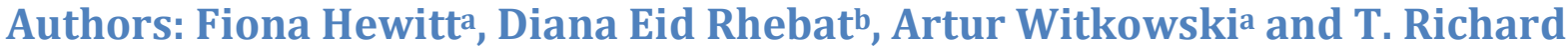 \\ Hulla
}

\author{
a Centre for Fire and Hazards Science, University of Central Lancashire, Preston, PR1 2HE, UK \\ b Fire and Safety Engineering Department, Prince Al-Hussein Bin Abdullah II Academy of Civil \\ Protection, Adh Dhuhayba Ash Sharqiyya, Jordan
}

\begin{abstract}
Recent studies have identified acetone as an unexpected pyrolysis product of EVA containing aluminium or magnesium hydroxide fire retardants. It is thought that the freshly formed, open-pored, metal oxide, a thermal decomposition product of the metal hydroxide, traps acetic acid released from EVA and catalyses its conversion to acetone. Such a ketonisation reaction is well-established but the intermediate steps that result in acetic acid conversion to acetone in the presence of a metal oxide, trapped within the polymer matrix, have not been reported. This study used three model metal acetates: aluminium acetate, magnesium acetate and calcium acetate, to chemically represent the proposed metal acetate intermediate complexes. This provides crucial information on the kinetics of acetic acid trapping and subsequent acetone release during decomposition studied by TGA-FTIR, which has been used to generate kinetic models within a pyrolysis programme (ThermaKin), in order to quantitatively understand the processes occurring in fire retardant EVA. The benefit of using metal acetates is that they are simple enough to allow isolation of the chemical process of interest from the complications of acetic acid release from EVA and transport through the polymer matrix.
\end{abstract}

\section{Introduction}

Ethylene-vinyl acetate co-polymer (EVA) is a widely used elastomeric polymer with a range of applications, including solar cells, adhesives and as a halogen-free replacement for poly (vinyl chloride) (PVC) in cable sheathing materials [1]. EVA with metal hydroxide (EVA-MH) is the world's second largest cable sheathing material, after PVC, both by value and volume. The global market for halogenfree cable compounds is approximately $€ 400$ million, of which EVA-MH is around $€ 300$ million. The chemical structure of EVA is that of polyethylene (PE) with a number of hydrogen atoms replaced by acetate side chains (Figure 1). The vinyl acetate content can vary considerably and influences the physical properties and subsequent applications of the polymer. EVA with vinyl acetate contents ranging from $14-28 \%$ by weight are most commonly reported [2,3]. Like PE, EVA is inherently flammable so reduction of flammability through the incorporation of fire retardants (FRs) is often necessary. Mineral fillers are well-established halogen-free FRs, however, their main limitation is the requirement for high loading, which can adversely affect processing and desirable physical properties of the host polymer. The polarity of EVA, imparted through the acetate side chains, and its elastomeric 
nature, enables it to accept relatively high loadings of mineral filler, without detriment to its physical properties.

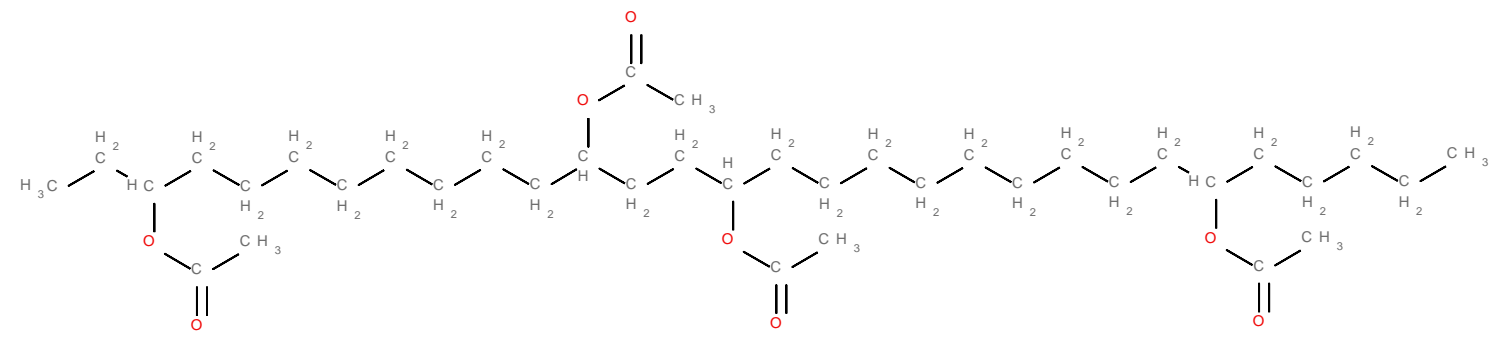

Figure 1 Chemical structure of ethylene-vinyl acetate copolymer

Aluminium hydroxide $\left(\mathrm{ATH}-\mathrm{Al}(\mathrm{OH})_{3}\right)$, is currently the most commonly used $\mathrm{MH} \mathrm{FR}$, due to its low cost and the high loadings required. It decomposes endothermically at $180-200{ }^{\circ} \mathrm{C}$ releasing water and leaving an aluminium oxide residue. The water release has a cooling effect and dilutes the pyrolysis gases, while the aluminium oxide remains in the condensed phase and can act as a barrier to heat and mass flux [4]. Magnesium hydroxide ( $\left.\mathrm{MDH}-\mathrm{Mg}(\mathrm{OH})_{2}\right)$ is another typical mineral filler FR that also decomposes endothermically with the release of water, at a higher temperature of approximately $300^{\circ} \mathrm{C}[5]$. Calcium hydroxide $\left(\mathrm{CDH}-\mathrm{Ca}(\mathrm{OH})_{2}\right)$ decomposes at higher temperatures still $\left(>400{ }^{\circ} \mathrm{C}\right.$ ) but is not generally considered such an effective fire retardant due to the exothermic reaction of the calcium oxide with carbon dioxide, resulting in the formation of calcium carbonate [5]. However, a recent study found promising FR behaviour of calcium-based hydrated minerals, such as $\mathrm{CDH}$ and dolimes (mixtures of $\mathrm{MDH}$ and $\mathrm{CDH}$ ), in EVA and PE [6]. Cone calorimetry found peak heat release rates (pHRRs) similar to, or better than, EVA-MDH and PE-MH, and a cohesive intumescent mineral residue was formed as a result of the carbonation reaction of $\mathrm{CDH}$ to form calcium carbonate.

The thermal decomposition mechanism of virgin EVA is well documented: chain stripping of the acetate side groups releases acetic acid at $\sim 300^{\circ} \mathrm{C}$ and subsequent polyene decomposition occurs at $\sim 400{ }^{\circ} \mathrm{C}$ and above $[1,7]$. The flammability properties of EVA-metal hydroxide composites (EVA-MHs) have also been extensively reported, however, the understanding of the chemical mechanisms involved in their thermal decomposition is more limited. Several recent studies have reported the somewhat unexpected detection of acetone as a pyrolysis product of EVA-MHs. This was initially described by Witkowski et al. in 2012 and has since been corroborated by other research $[8,9,10]$. Results from EVA-ATH suggested competitive release between acetic acid and acetone, where acetone release is favoured at higher heat flux/temperature. It is thought that the freshly formed metal oxide, a result of the thermal decomposition of the $\mathrm{MH}$, catalyses and traps acetic acid released from EVA with subsequent conversion to acetone. Around 100 years ago, acetone was synthesised by passing acetic acid over heated calcium oxide in a ketonisation reaction, shown in Figure 2(a) [8]. Other metal oxides are known to catalyse this reaction similarly.

(a) 


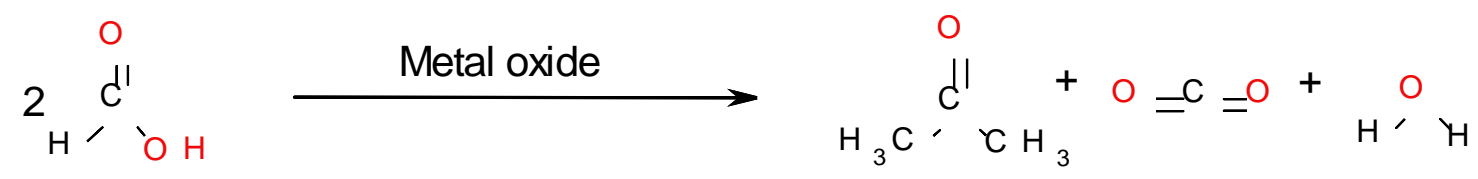

(b)

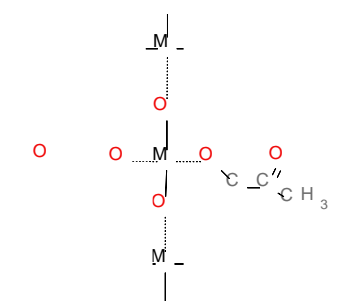

Figure 2(a) Ketonisation reaction and (b) proposed metal-acetate complex

In the case of thermally decomposing EVA-MHs, the acetic acid is a pyrolysis product from the EVA and the metal oxide is formed by the corresponding mineral filler. Figure 2(b) proposes a metalacetate complex that results from interaction between the acetate groups and the metal atom within the metal oxide. It is postulated that this interaction delays the release of the acetate groups as acetic acid, and provides a pathway for acetone release through ketonisation. While the ketonisation reaction is well-established, to the best of our knowledge, there is no literature describing the intermediate steps that result in acetic acid conversion to acetone in the presence of a metal oxide for EVA-MHs.

(a)

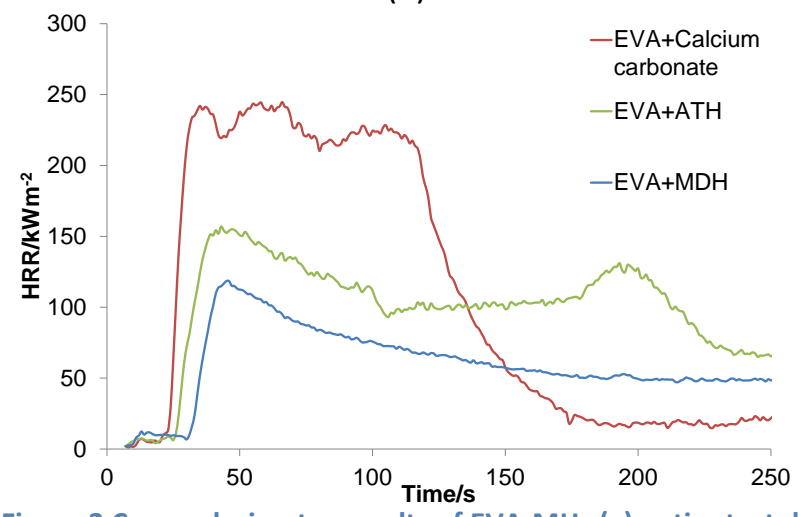

(b)

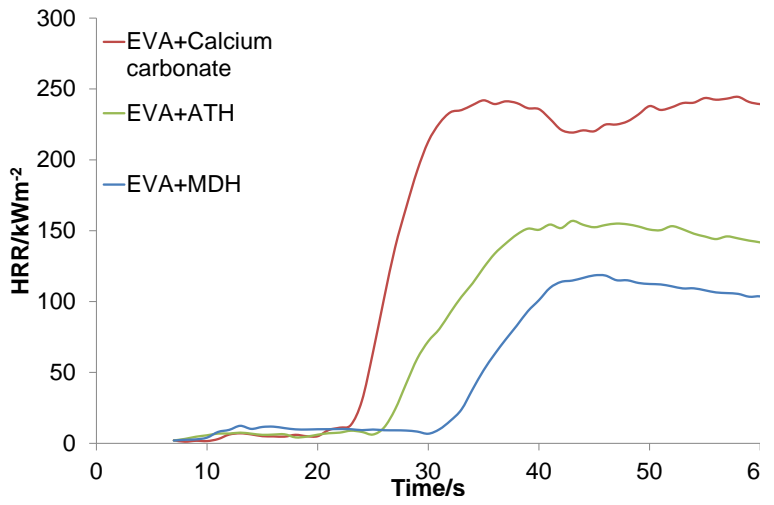

Figure 3 Cone calorimeter results of EVA-MHs (a) entire test duration, (b) expanded view of ignition time [11]

The generation of acetone from EVA-MHs is important in terms of fire-retardancy, because the trapping and conversion of acetic acid that occur prior to acetone release is relatively slow and results in delayed fuel release. Extensive studies have been undertaken to understand the decomposition mechanism of EVA-MHs $[12,13,14]$. The combustion of EVA starts with a sharp peak in the heat release rate curve, attributed to the loss of acetic acid. In the decomposition of certain EVA composites, including EVA-ATH and EVA-MDH, this "acetic acid" has been shown to be a mixture of acetic acid and acetone, in many cases dominated by acetone. This initial fuel release can result in early surface spread of flame, while its suppression can result in cable sheathing materials able to meet European regulatory requirements (e.g. Euroclass B). Figure 3 shows cone calorimeter results from three EVA-mineral filler composites: EVA-calcium carbonate $\left(\mathrm{CaCO}_{3}\right)$, EVA-ATH and EVA-MDH [11]. EVA-CaCO 3 behaves as a control because it does not decompose endothermically or at a similar 
temperature to EVA, but it ensures the three formulations contain comparable EVA content. Acetic acid is responsible for the heat release rate (HRR) peak in the $\mathrm{CaCO}_{3}$ filled sample, as conversion to acetone does not occur in the absence of a suitable catalyst, e.g. a metal oxide. Ignition of EVA-ATH and EVA-MDH samples are delayed by approximately three and nine seconds respectively, compared to the EVA-CaCO . The HRRs for EVA-ATH and EVA-MDH increase more slowly and the peak HRRs are

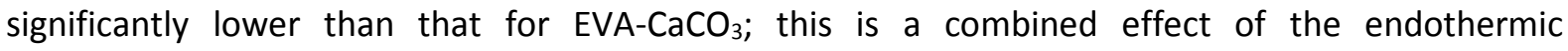
decomposition of the $\mathrm{MH}$, the water release and, crucial to this work, the delay as acetic acid is trapped in the porous metal oxide, prior to release as acetone. Total heat release is the only flammability property that would be unaffected by the ketonisation reaction. Thermochemically, there is no advantage to acetone release over acetic acid, as the heat released by one molecule of acetone $(-1785 \mathrm{~kJ})$ is equivalent to that released by two of acetic acid $(2 \times-876.1=-1752)$ [8].

This work investigates the thermal decomposition of three metal acetates: aluminium acetate (AIAC), magnesium acetate $(\mathrm{MgAc})$ and calcium acetate $(\mathrm{CaAc})$, which are model compounds of the proposed metal acetate complex in Figure 2 (b). This is done with the aim of correlating the decomposition products of the acetates to those from EVA-MHs to test the hypothesis that EVA-MHs decompose via these intermediate complexes. The metal acetates are simpler compounds than EVA-MHs (which can contain varying acetate contents trapped within the polymer matrix) and should allow the acetic acid to acetone step to be studied in isolation. This will provide evidence relating to chemical mechanisms of EVA-MHs thermal decomposition, and the temperatures at which these occur.

\section{Experimental}

\section{1 Materials}

Basic aluminium acetate, magnesium acetate tetrahydrate and calcium acetate monohydrate were obtained from Sigma Aldrich. Aluminium acetate and calcium acetate were fine powders while magnesium acetate was supplied as crystals of approximately $1 \mathrm{~mm}$ diameter. An EVA-ATH blend from Leoni Stüder was also used for the final stage of the investigation.

Table 1 Information on the acetate samples used in the investigation

\begin{tabular}{|l|l|}
\hline Name & Chemical formula \\
\hline $\begin{array}{l}\text { Magnesium acetate } \\
\text { tetrahydrate }(\mathrm{MgAc})\end{array}$ & $\mathrm{Mg}\left(\mathrm{CH}_{3} \mathrm{COO}\right)_{2} \cdot 4 \mathrm{H}_{2} \mathrm{O}$ \\
\hline $\begin{array}{l}\text { Calcium acetate monohydrate } \\
\text { (CaAc) }\end{array}$ & $\mathrm{Ca}\left(\mathrm{CH}_{3} \mathrm{COO}\right)_{2} \cdot \mathrm{H}_{2} \mathrm{O}$ \\
\hline $\begin{array}{l}\text { Basic aluminium acetate } \\
\text { (AlAc) }\end{array}$ & $\mathrm{Al}(\mathrm{OH})\left(\mathrm{CH}_{3} \mathrm{COO}\right)_{2}$ \\
\hline
\end{tabular}

\subsection{Methods}

\subsubsection{TGA-FTIR}

A simultaneous thermal analyser (STA) (Stanton-Redcroft) was connected via a heated transfer line to an FTIR (Nicolet Magna IR Spectrometer 550). Samples of $15 \mathrm{mg}$ were used for the TGA-FTIR experiments, which were carried out in duplicate. Such a sample mass is greater than conventionally used in TGA experiments (conventionally $10 \mathrm{mg}$ ) - this decision was made in order to improve the signal to noise ratio of the FTIR spectra. Samples were heated at 5,10 and $20^{\circ} \mathrm{C} \mathrm{min}^{-1}$ in nitrogen up 
to $800{ }^{\circ} \mathrm{C}$ to investigate whether the pyrolysis products were affected by heating rate. The samples were decomposed in a platinum crucible and the nitrogen flow was set to $50 \mathrm{~cm}^{3} \mathrm{~min}^{-1}$. The transfer line was connected to the gas outlet and maintained at $220^{\circ} \mathrm{C}$ to prevent condensation of volatiles as they flowed from the STA to the FTIR gas cell. The FTIR gas cell was held at $280^{\circ} \mathrm{C}$ and the spectrometer resolution was set to $2 \mathrm{~cm}^{-1}$ with a $20 \mathrm{~s}$ scanning rate. Spectral analysis was performed in OMNIC version 7.3 and reference spectra for acetic acid, acetone and water were obtained by analysing these under the same conditions as the acetate samples. Reference spectra for carbon dioxide and carbon monoxide were taken from the HR Nicolet TGA Vapour Phase library.

\subsubsection{ThermaKin}

ThermaKin is a pyrolysis modelling software developed by Stoliarov and Lyon [15]. It uses chemical kinetics to describe transient thermal energy transport and material transformations. Mass and energy conservation equations are employed to predict the temperature and volume of the material for the duration of the simulation. Materials are defined using components, each of which has specified physical and thermal properties. Decomposition is described by a number of reactions. To create the microscale models used in this work, chemical stoichiometry and the kinetic parameters ( $E_{a}$ and $\left.A\right)$ were input for each reaction in the model. The TGA experiments, from which the kinetic parameters were derived, were carried out in triplicate at $10{ }^{\circ} \mathrm{C} \mathrm{min}^{-1}$ (in nitrogen at $50 \mathrm{~cm}^{3} \mathrm{~min}^{-1}$ ) using $10 \mathrm{mg}$ samples. The sample mass was lower than in the TGA-FTIR experiments to reduce the risk of thermal and concentration gradients arising during decomposition [16]. Validation of the kinetic parameters was carried out by running simulations at 5 and $20^{\circ} \mathrm{C} \mathrm{min}^{-1}$ and comparing the results with TGA data obtained, also from $10 \mathrm{mg}$ samples in nitrogen, at the corresponding heating rates. The EVA-ATH was heated at $10 \mathrm{C} \mathrm{min}^{-1}$ only.

The method of deriving the kinetic parameters for each reaction from the TGA data was heavily based on the single point method (SPM) reported by Lyon et al. in 2011 [17]. This method assumes that mass loss rate is equivalent to rate of fuel release and that the decomposition occurs as a first order process and has been used with ThermaKin by Stoliarov's group at the University of Maryland [18]. The rate constant, $k$, is assumed to take the Arrhenius form where there are two unknowns: activation energy $\left(E_{a}\right)$ and the pre-exponential factor $(A)$. To find $A$, a value of $E_{a}$ can be fixed, either using an arbitrary value that can be adjusted or using the following equation:

$$
E_{a}=\frac{x^{\prime} \max }{1-\mu} \frac{e R T_{p}^{2}}{\beta}
$$

$\boldsymbol{X}_{\max }^{\prime}=(d x / d t)_{\max }-$ the value for a reaction's peak mass loss rate (pMLR)

$T_{p}=$ temperature at which pMLR occurs

$\boldsymbol{x}=$ fraction of original sample mass remaining at $T_{p}$, i.e., if $43 \%$ of the weight remains at $T_{p}$ then

$x=0.43$

$\mathbf{R}=$ Gas constant $\left(8.314 \mathrm{~J} \mathrm{~mol}^{-1} \mathrm{~K}^{-1}\right)$

Once $E_{a}$ is fixed, the Arrhenius equation can be transformed, as follows, to find $A$ :

$$
A=\left(\frac{x^{\prime} \max }{x}\right) /\left(\exp \left(-\left(\frac{E_{a}}{8.314} \times T_{p}\right)\right)\right)
$$


The Arrhenius parameters of $E_{a}$ and $A$ were adjusted incrementally to attain desired changes in the temperature and magnitude of each MLR peak. Further details can be found in reference [17]. The difference between the experimental and simulated mass curves was quantified by calculating the relative standard deviation (RSD \%) between the values recorded at each time-step. Models were considered acceptable when the maximum RSD value was below $15 \%$ and the average of all RSD values was below $5 \%$.

\section{Results and discussion}

\subsection{TGA-FTIR}

Figure 4 shows the mass loss and mass loss rate (MLR) of the three acetate samples at 5,10 and $20^{\circ} \mathrm{C} \mathrm{min}^{-1}$ during thermogravimetric analysis. Increasing the heating rate increased the temperature at which each mass loss step is recorded. Lower heating rates give components more time to reach equilibrium and individual mass loss steps are most likely to be well-defined [19]. Higher heating rates reduce the probability of attaining equilibrium and introduce a risk of thermal lag - temperature differences between the sample and apparatus, particularly the sample and the furnace (the data handling system records furnace temperature). A heating rate of $10^{\circ} \mathrm{C} \mathrm{min}^{-1}$ is a common compromise: used in fire science it is low enough to attain thermal equilibrium within the sample, but high enough to reflect the dynamic processes occurring in a fire.

The mass loss curves of AlAc initially indicate two mass loss steps $\left(\sim 80-180{ }^{\circ} \mathrm{C}\right.$ and $\sim 140-550{ }^{\circ} \mathrm{C}$ ), but inspection of MLR finds that there is a third mass loss associated with the decomposition (at 285 $-315^{\circ} \mathrm{C}$, depending on heating rate). The decomposition of MgAc appears to occur with three mass loss steps, although the MLR curves show that the most significant mass loss $\left(\sim 380^{\circ} \mathrm{C}\right)$ in two steps at lower heating rates. Thermal and concentration gradients within the sample show this mass loss as one step at $20^{\circ} \mathrm{C} \mathrm{min}^{-1}$. The MgAc sample was more susceptible to such gradients due to the larger particle size compared to AIAc and CaAc. CaAc shows five distinct decomposition steps. For all samples, mass loss occurring between $\sim 100-200^{\circ} \mathrm{C}$ can be attributed to the loss of water.

(a)

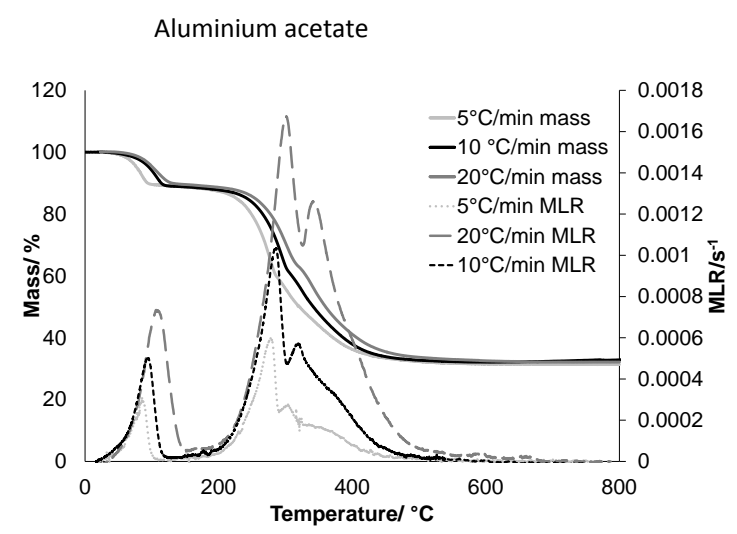

(b)

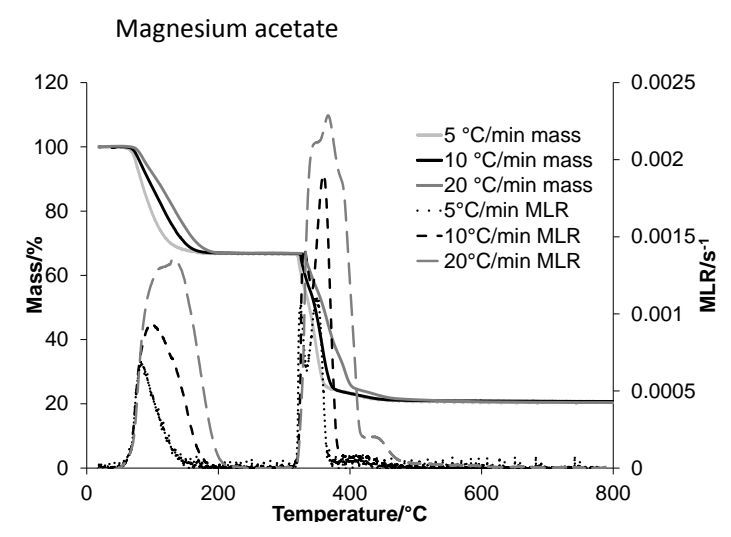

(c) 


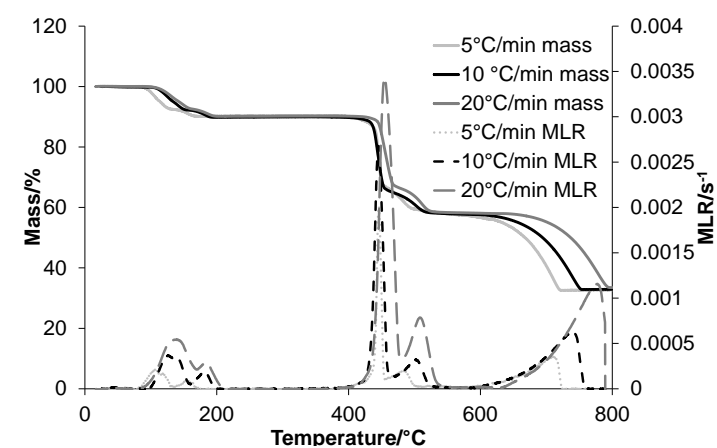

Figure 4 Mass loss and MLR curves of (a) aluminium acetate, (b) magnesium acetate and (c) calcium acetate during thermogravimetric analysis at 5,10 and $20^{\circ} \mathrm{C} \mathrm{min}^{-1}$ in $\mathrm{N}_{2}$

Figure 5 represents the mass loss data for the three samples at $10{ }^{\circ} \mathrm{C} \mathrm{min}^{-1}$. The data were rescaled to omit water loss and directly compare acetic acid/acetone release. This demonstrates clearly that thermal stability increased from AlAc to MgAc, and from MgAc to CaAc. CaAc and AlAc yielded approximately equal quantities of residue ( $33 \%$ ) while MgAc formed less ( $21 \%$ ). The order of increasing thermal stability (from AlAc to $\mathrm{CaAc}$ ) correlates with that of the corresponding metal hydroxides, as discussed in the introduction.

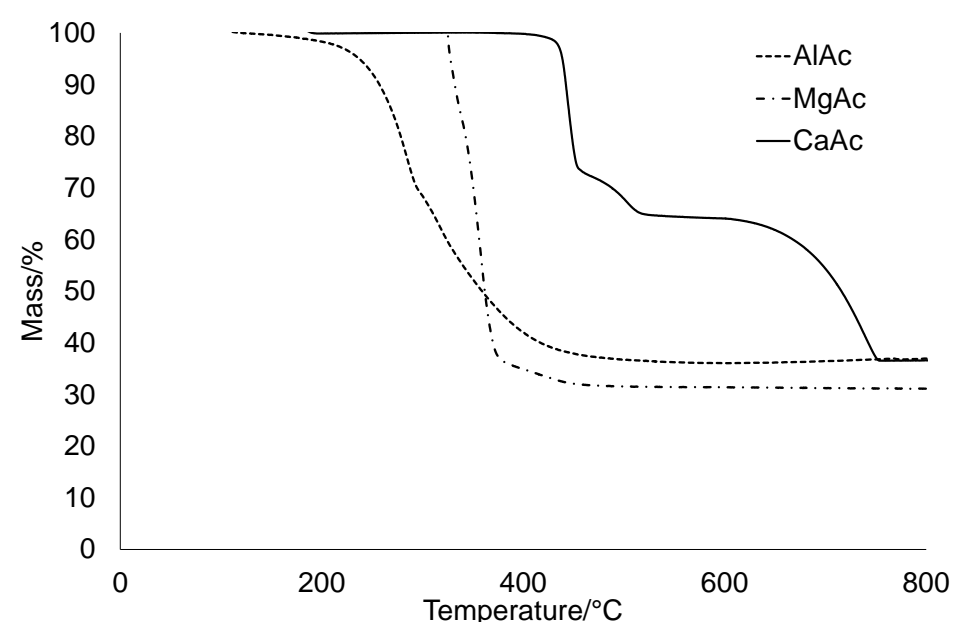

Figure 5 Rescaled (water omitted) mass loss data for aluminium, magnesium and calcium acetate during thermogravimetric analysis at $10^{\circ} \mathrm{C} \mathrm{min}^{-1}$ in $\mathrm{N}_{2}$

The gas-phase FTIR results identify the pyrolysis products from each acetate sample. Real-time monitoring of the gaseous pyrolysis products allowed time resolved separation of each gas evolved during the thermal decomposition. The output data can take several forms. A Gram-Schmidt plot shows an overall profile of the volatiles released as a function of time and generally reflects the mass loss rate (MLR) curve from the corresponding TGA experiment. A particular time point (usually a point of peak volatiles release) on the Gram-Schmidt then can be selected to display the spectrum. Profiles can also be generated to show the release of individual volatiles over the full temperature range. This is useful for studying the release of product gases relative to one another. Heating rate did not affect the identity of the volatiles released from the acetates, therefore the FTIR data is presented for $5{ }^{\circ} \mathrm{C} \mathrm{min}-1$ only as these show optimum gas separation. 


\section{Aluminium acetate}

Figure 6(a) shows the FTIR spectra collected at the points of peak volatile release and identifies the products of each mass loss step from the TGA. The first gas detected was water (broad absorption between 1268 and $1879 \mathrm{~cm}^{-1}$ ) with peak release at around $92^{\circ} \mathrm{C}$. Acetic acid was then identified, which peaked almost $200{ }^{\circ} \mathrm{C}$ higher at $284^{\circ} \mathrm{C}$. The strongest absorption bands for acetic acid were found at 1798, 1775 and $1181 \mathrm{~cm}^{-1}$. An additional absorption occurred at $3582 \mathrm{~cm}^{-1}$, corresponding to the hydroxyl stretch. The increase of the $\mathrm{CO}_{2}$ peak $\left(2305 \mathrm{~cm}^{-1}\right)$ at $306{ }^{\circ} \mathrm{C}$, as well as the slight broadening of the carbonyl peak $\left(\sim 1775 \mathrm{~cm}^{-1}\right)$ indicates the beginning of acetone release. This is corroborated by the volatiles' profiles, which found a mixture of gases at this point: acetic acid, acetone and $\mathrm{CO}_{2}$. The profiles in Figure $6(\mathrm{~b})$ show that acetone release peaks as acetic acid release declines; this agrees with the findings of Ngohang et al. from FTIR analysis on gaseous pyrolysis products from EVA-ATH under external heat flux from a controlled atmosphere mass loss calorimeter (CAMLC) [10]. It was suggested that because the activation energy for acetone release from EVA-ATH is higher than that of acetic acid release, acetic acid was detected at lower temperatures and acetone at higher temperatures. This will be discussed further in section 3.2.1 where the kinetic parameters associated with AlAc pyrolysis are considered. By $337^{\circ} \mathrm{C}$ the spectrum shows further broadening of the carbonyl peak, characteristic of acetone, but the peak at $1796 \mathrm{~cm}^{-1}$ indicates that acetic acid was still present. It is difficult to visually differentiate the peak at $\sim 1200 \mathrm{~cm}^{-1}$, however, for acetic acid, this peak has maximum absorption at $\sim 1180 \mathrm{~cm}^{-1}$ and for acetone it shifts slightly to $1214 \mathrm{~cm}^{-1}$. At $337^{\circ} \mathrm{C}$, this peak has maximum absorption at $1200 \mathrm{~cm}^{-1}$, an intermediate value between the two, supporting the observation that both acetic acid and acetone were detected together. At around $365{ }^{\circ} \mathrm{C}$ there is no evidence of acetic acid: the bands at 3582, 1796 and $990 \mathrm{~cm}^{-1}$ are no longer visible and the carbonyl peak has shifted to a lower wavenumber $\left(1740 \mathrm{~cm}^{-1}\right)$ as is characteristic of ketones. The only pyrolysis products seen at this point are therefore acetone and $\mathrm{CO}_{2}$. Given the ketonisation reaction, it is likely that water is also evolved at this point, but the signal was masked by the acetone peaks. Figure 7 shows that water and acetone absorb IR radiation across a very similar wavenumber range, except at where water exclusively absorbs at $1509 \mathrm{~cm}^{-1}$. This peak is absent from the spectrum at $\sim 365{ }^{\circ} \mathrm{C}$, but the FTIR automatically subtracted the background taken before heating, so it is likely that quantities of water, too small to appear on this spectrum, were evolved at this point. $\mathrm{CO}_{2}$ release closely followed acetone release, providing further evidence for the ketonisation reaction.

(a)

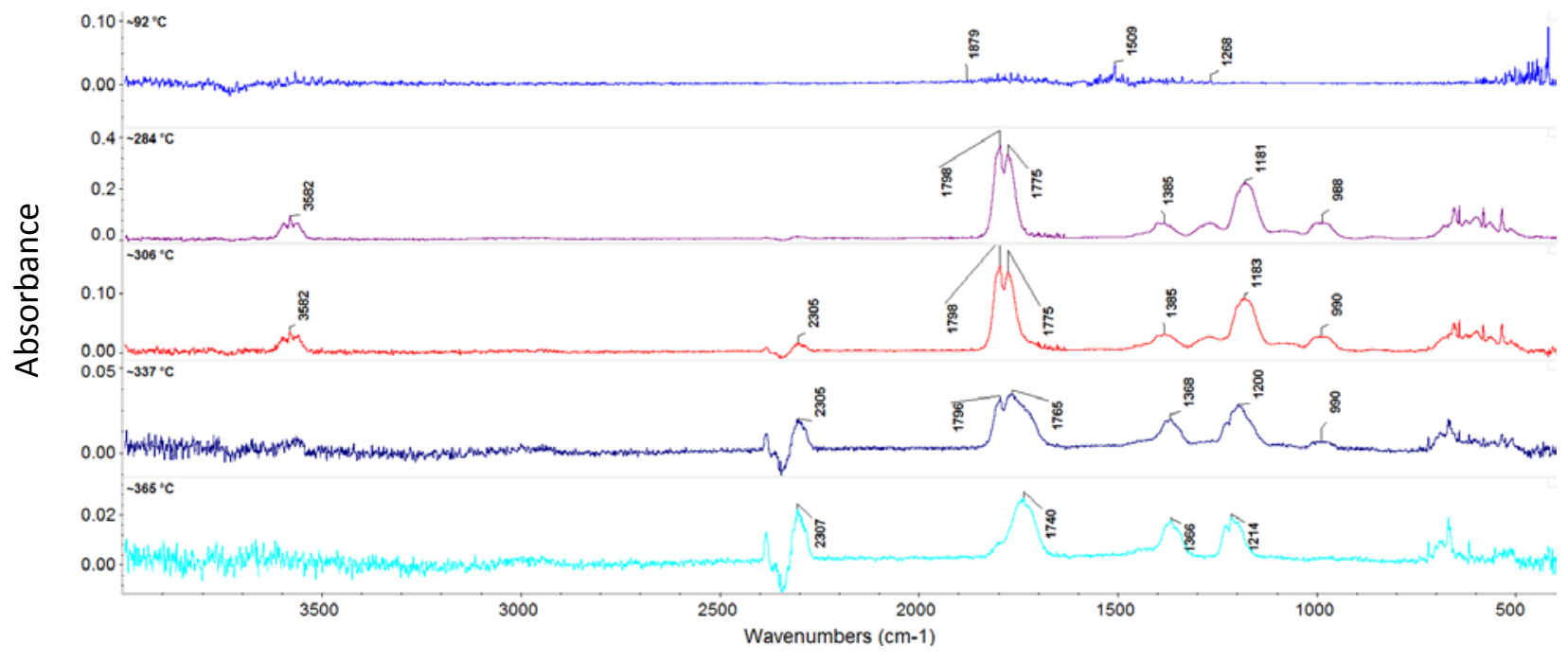


(b)

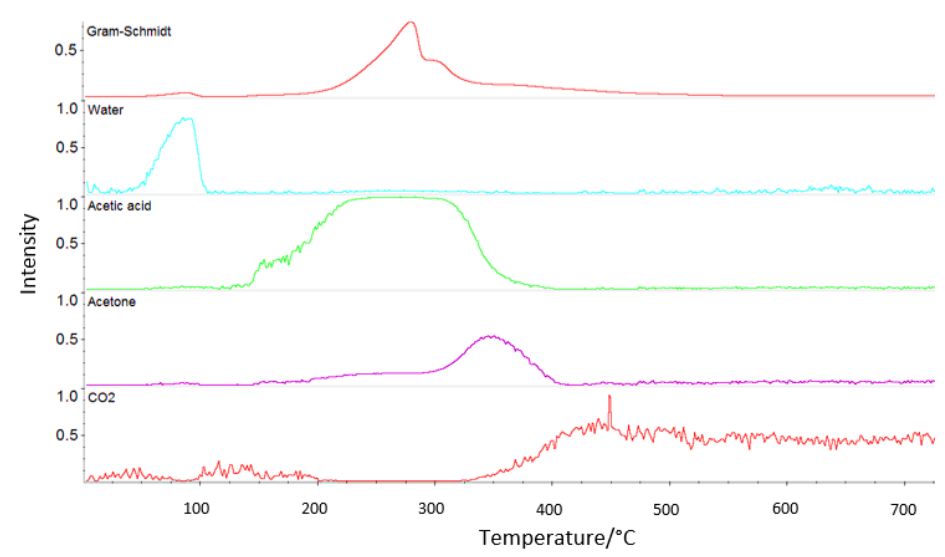

Figure 6 (a) FTIR spectra obtained from the analysis of the pyrolysis gases released from aluminium acetate heated at $5^{\circ} \mathrm{C} \mathrm{min}^{-1}$ in $\mathrm{N}_{2}$ during thermogravimetric analysis, and (b) total and individual volatiles' profiles generated from the same test

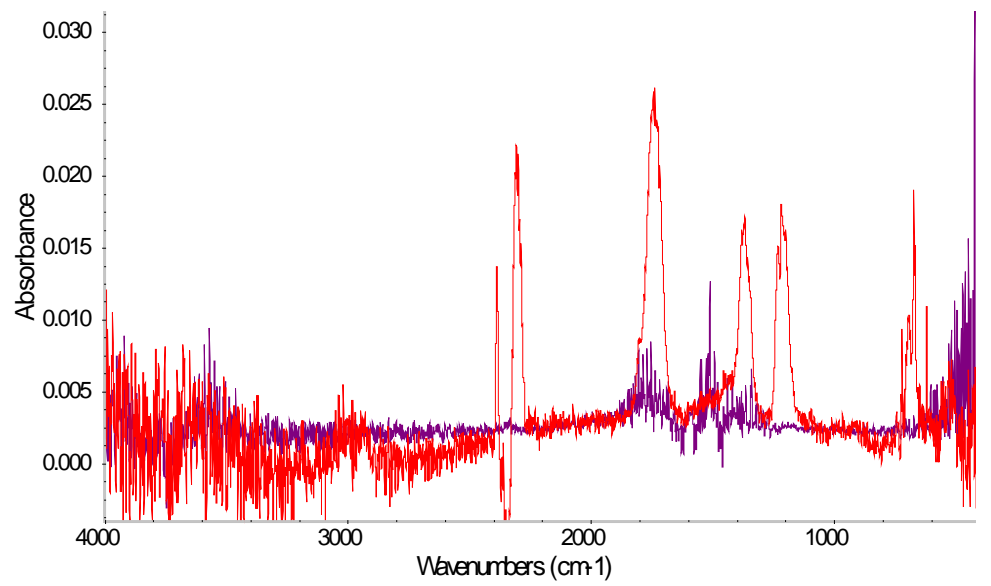

Figure 7 Resultant spectrum containing acetone (red) and reference spectrum of water (purple) overlaid

\section{Magnesium acetate}

The first gaseous product released was water $\left(1268-1881 \mathrm{~cm}^{-1}\right)$, from the dehydration of the water of crystallisation (Figure $8(a)$ ). Following this, the compound was thermally stable with no volatiles released until almost $350{ }^{\circ} \mathrm{C}$. At this point acetone $\left(1738,1366\right.$ and $\left.1212 \mathrm{~cm}^{-1}\right)$, water and $\mathrm{CO}_{2}$ $\left(2303 \mathrm{~cm}^{-1}\right)$ were detected. Another peak on the Gram-Schmidt followed closely at $\sim 386{ }^{\circ} \mathrm{C}$, where the same products were found (Figure $8(\mathrm{~b})$ ). It is unclear why the loss of these products occurs in two stages - at $5{ }^{\circ} \mathrm{C} \mathrm{min}^{-1}$ it is unlikely that there would have been a thermal gradient within the sample and the effect of particle size was tested by grinding the MgAc crystals to a fine powder, however, the same phenomenon was observed (Figure 9). One theory is that two acetate groups attached to the same $\mathrm{Mg}$ ion, and when one was released the other was bound more tightly and released at higher temperatures. $\mathrm{CO}_{2}$ and acetone were released simultaneously, providing evidence for the ketonisation reaction. Once acetone release tails off, $\mathrm{CO}_{2}$ continued to be evolved slowly (Figure $8(\mathrm{a})$ at $428^{\circ} \mathrm{C}$ ). 
(a)

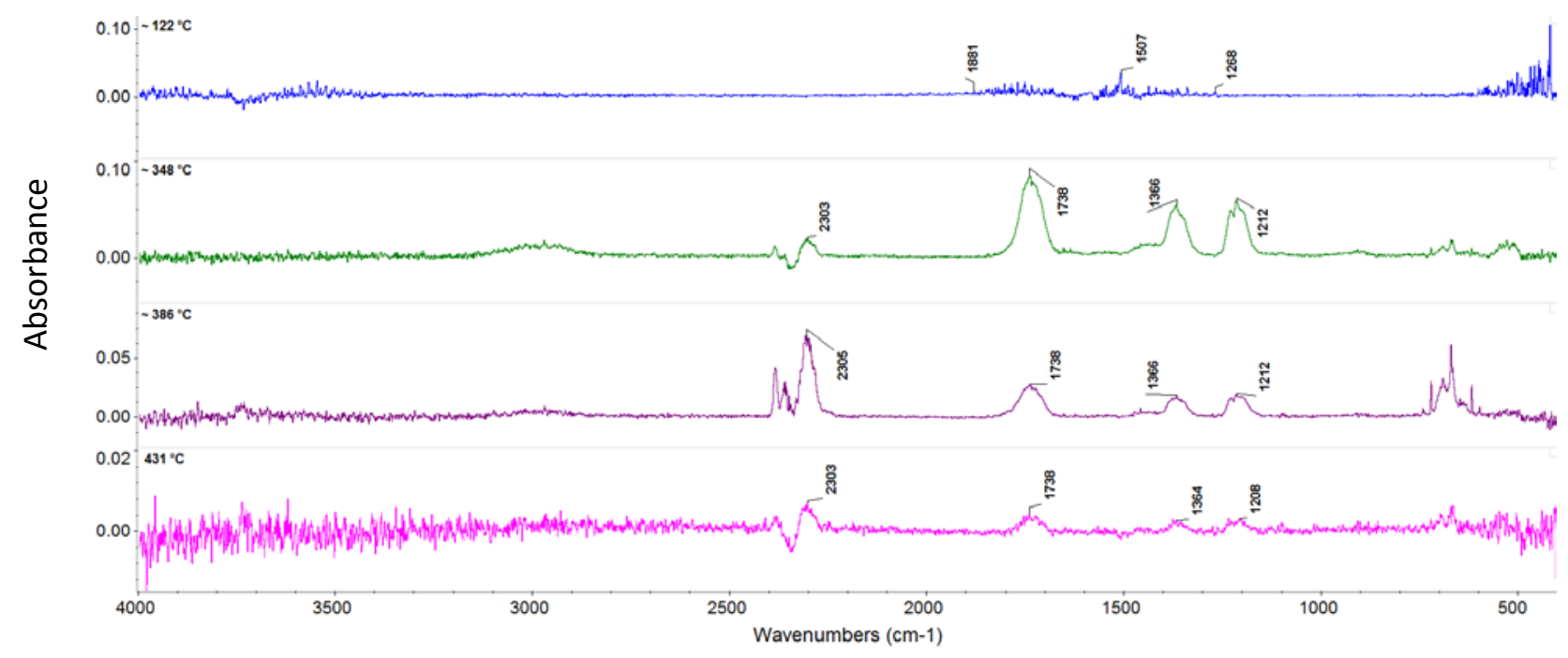

(b)

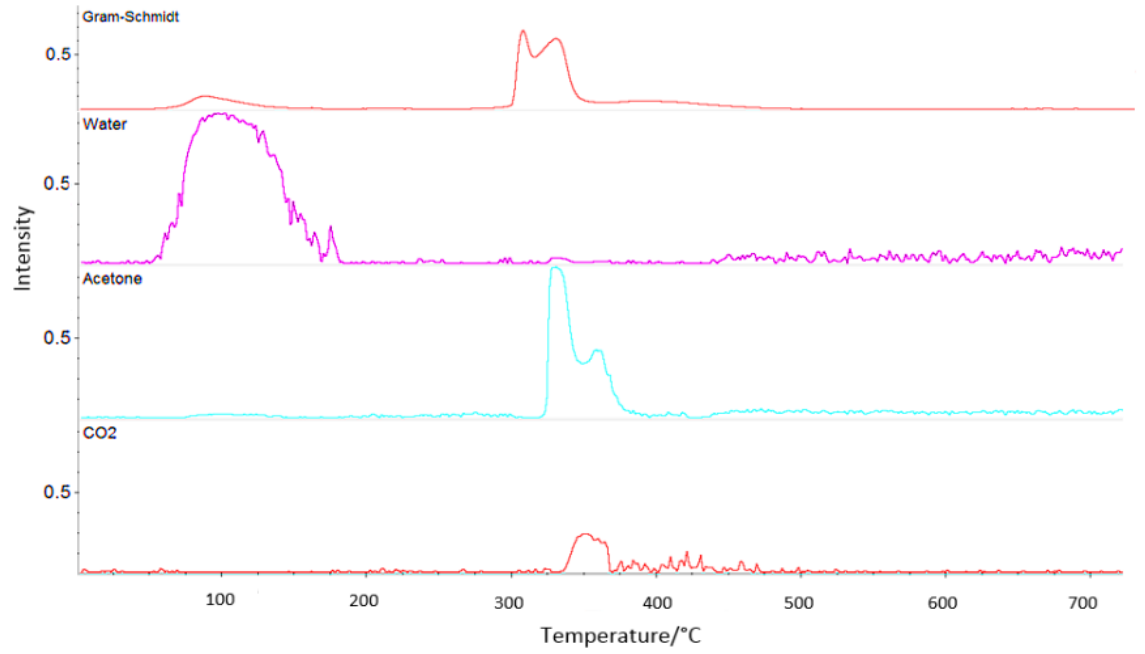

Figure 8 (a) FTIR spectra obtained from the analysis of the pyrolysis gases released from magnesium acetate heated at $5{ }^{\circ} \mathrm{C} \mathrm{min}^{-1}$ in $\mathrm{N}_{2}$ during thermogravimetric analysis, and (b) total and individual volatiles' profiles generated from the same test

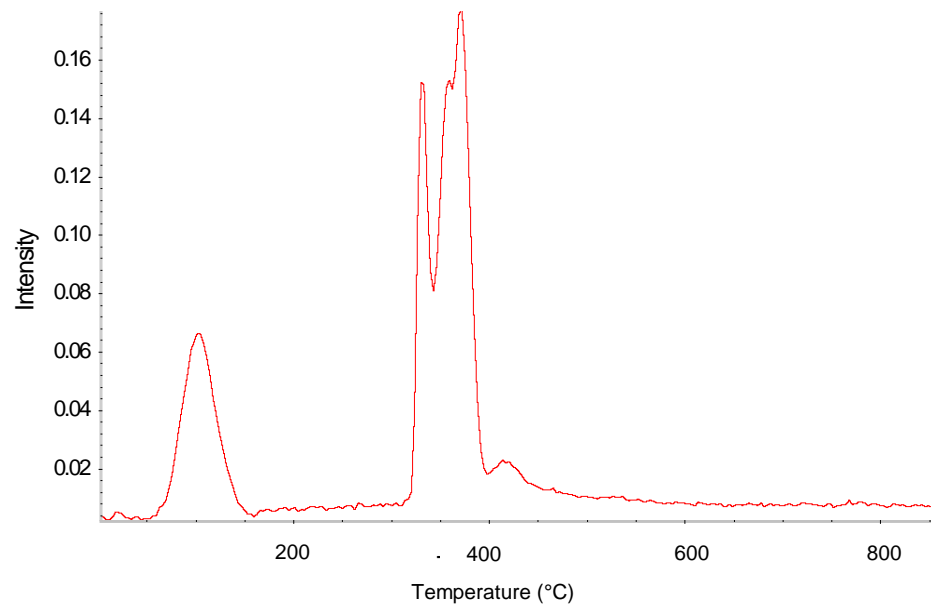

Figure 9 Total volatiles' (Gram-Schmidt) profile of finely ground $\mathrm{MgAc}\left(10^{\circ} \mathrm{C} \mathrm{min}^{-1}, \mathrm{~N}_{2}\right)$ 


\section{Calcium acetate}

Figure 10(a) identifies the products from each stage of mass loss. The volatiles' profiles (Figure 10(b)) show water release as two stages, with the first peak at $124^{\circ} \mathrm{C}$ and the second at $169^{\circ} \mathrm{C}$. CaAc is highly hygroscopic and the common form is the monohydrate, as used in this study. Even the monohydrate is hygroscopic so this two-stage release of water is probably related to additional atmospheric water on the sample surface [20]. No mass was lost from $\sim 200-400{ }^{\circ} \mathrm{C}$. At $\sim 450{ }^{\circ} \mathrm{C}$ a sharp peak of volatile release was seen; the spectrum at this point was characteristic of acetone, water and carbon dioxide. Again, this is evidence of the ketonisation reaction. $\mathrm{CO}_{2}$ was released in the final stage of decomposition, which can be attributed to the formation of calcium carbonate followed by conversion of calcium carbonate to calcium oxide; this has been reported to occur at similar temperatures to those found in this study [4]. Unlike the other acetate samples, carbon monoxide (CO) was detected as a pyrolysis product of $\mathrm{CaAc}$ at $\sim 475^{\circ} \mathrm{C}$ (see Figure 11). In a study by Freudenheim that investigated the reaction of acetone heated with lime, $\mathrm{CO}$ was present and was attributed to the dissociation of acetone with additional products of methane, hydrogen and carbon [21]. Given the presence of acetone in the pyrolysis FTIR spectra of CaAc, this is possible, however, methane was not detected (note - hydrogen is transparent to IR radiation and would not be detected by this method in any quantity). Therefore the presence of $\mathrm{CO}$ in this case is either not a result of acetone dissociation, or the concentrations of methane were too low to detect in the FTIR. There is also no clear explanation as to why CaAc was the only acetate sample to produce carbon monoxide.

(a)

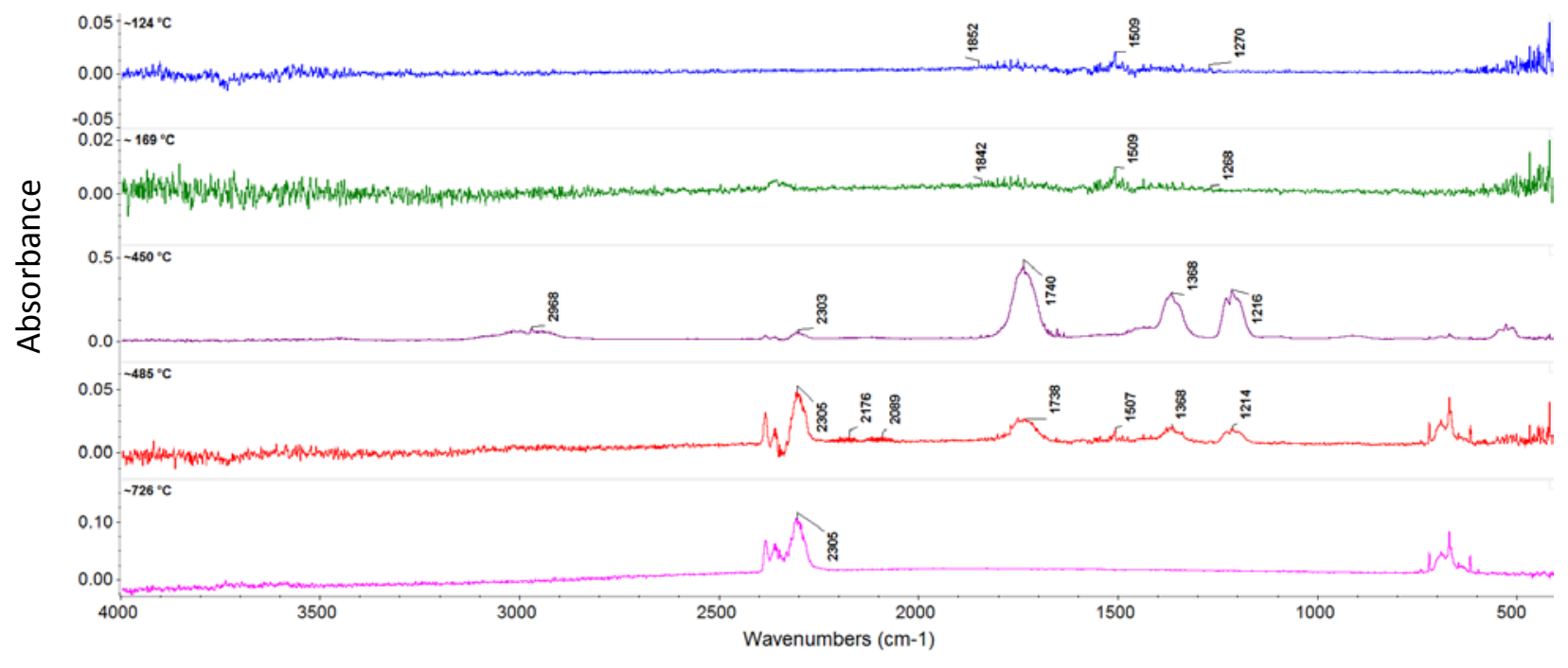


(b)

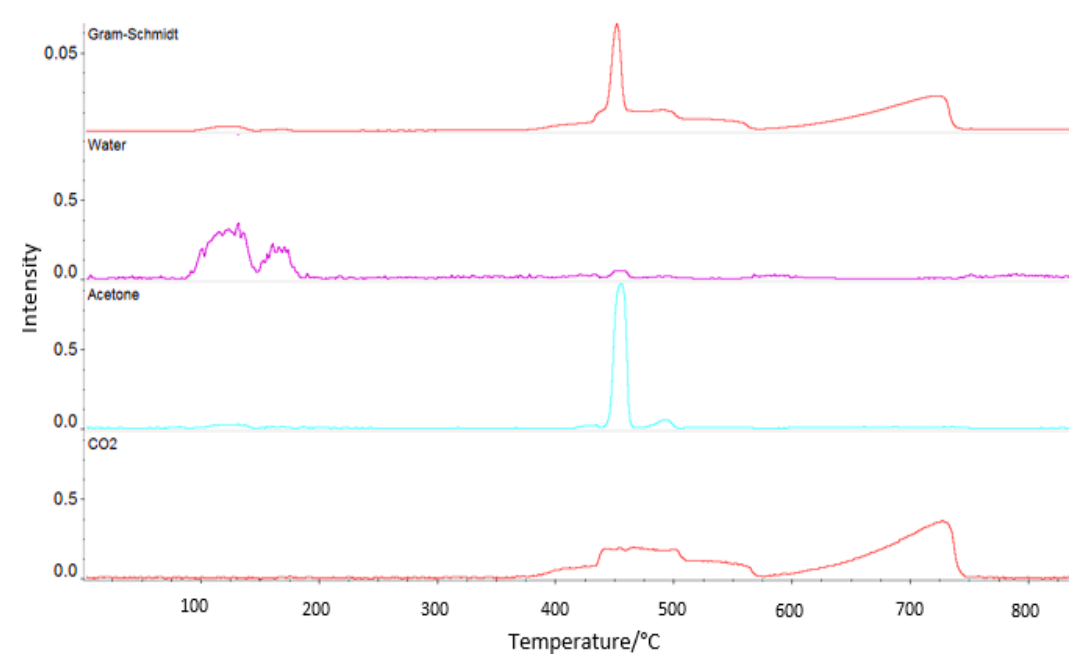

Figure 10 (a) FTIR spectra obtained from the analysis of the pyrolysis gases released from calcium acetate heated at $5{ }^{\circ} \mathrm{C} \mathrm{min}^{-1}$ in $\mathrm{N}_{2}$ during thermogravimetric analysis, and (b) total and individual volatiles' profiles generated from the same test

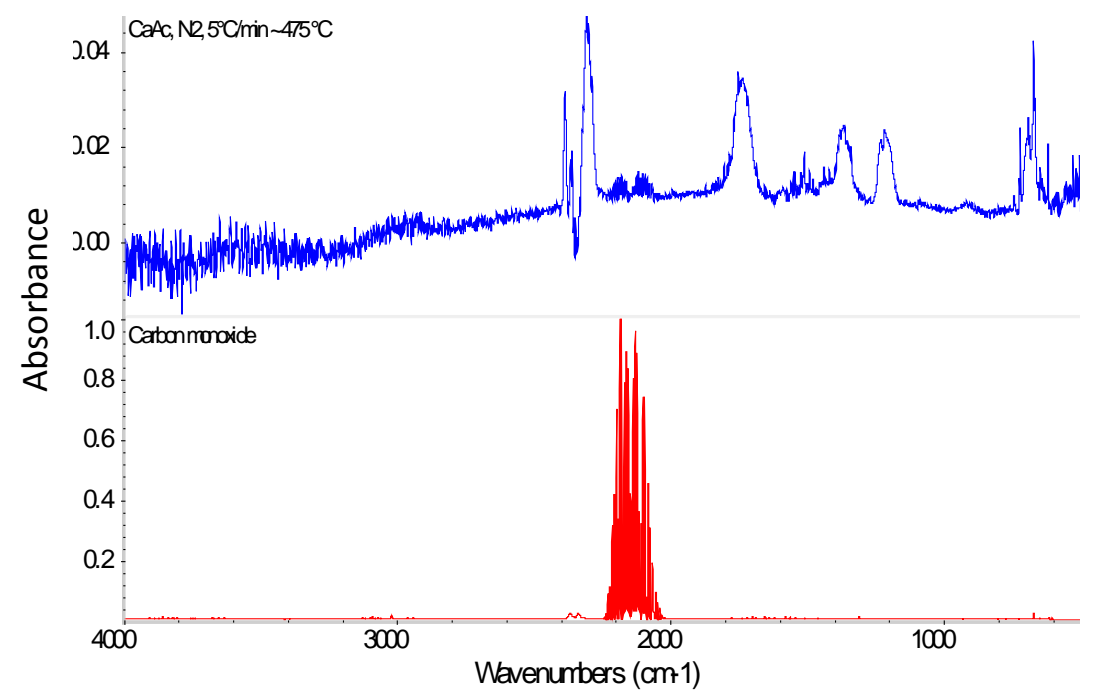

Figure 11 Spectrum of calcium acetate pyrolysis products (generated by thermogravimetric analysis in $\mathrm{N}_{2}$ at $5^{\circ} \mathrm{C} \mathrm{min}{ }^{-1}$ ) compared with the reference spectrum of carbon monoxide

Table 2 summarises the collection of pyrolysis products that were detected from the thermal decomposition of the three acetate samples. The products did not vary with heating rate. The pyrolysis products were largely the same for the three acetate samples, but with two significant differences: AlAc was the only sample to produce acetic acid and CaAc was the only sample to produce CO. It is possible that $\mathrm{CO}$ release from $\mathrm{CaAc}$ was a result of acetone dissociation but the other products that would be expected from that were not detected so the cause of carbon monoxide formation is, as yet, unexplained.

Table 2 Summary of the pyrolysis products detected from FTIR analysis of the gases released during thermogravimetric analysis

\begin{tabular}{|l|l|l|l|l|l|}
\hline & \multicolumn{4}{|c|}{ Pyrolysis products } \\
\hline $\begin{array}{l}\text { Metal } \\
\text { acetate }\end{array}$ & Water & $\begin{array}{l}\text { Acetic } \\
\text { acid }\end{array}$ & Acetone & Carbon dioxide & Carbon monoxide \\
\hline
\end{tabular}




\begin{tabular}{|l|l|l|l|l|l|}
\hline $\begin{array}{l}\text { Aluminium } \\
\text { acetate }\end{array}$ & $\mathrm{V}$ & $\mathrm{V}$ & $\mathrm{V}$ & $\mathrm{V}$ & \\
\hline $\begin{array}{l}\text { Magnesium } \\
\text { acetate }\end{array}$ & $\mathrm{V}$ & & $\mathrm{V}$ & $\mathrm{V}$ & \\
\hline $\begin{array}{l}\text { Calcium } \\
\text { acetate }\end{array}$ & $\mathrm{V}$ & & $\mathrm{V}$ & $\mathrm{V}$ & $\mathrm{V}$ \\
\hline
\end{tabular}

\subsection{ThermaKin microscale modelling}

To determine the reaction kinetics involved in the thermal decomposition of the acetate samples, and to glean further information about the chemical mechanisms, the TGA data were modelled using ThermaKin. Experimental and simulated data were primarily compared using mass loss rate (MLR) curves, as these make changes in mass more apparent than in the mass loss curve. Using MLR curves also improves the accuracy of identifying the peak pyrolysis temperatures $\left(T_{p}\right)$ for each stage. The models were optimised with the $10^{\circ} \mathrm{C} \mathrm{min}^{-1} \mathrm{TGA}$ data and validated by application to 5 and $20^{\circ} \mathrm{C} \mathrm{min}^{-1}$ data (sample mass $=10 \mathrm{mg}$ in all cases). Pyrolysis modelling is generally done on the microscale to obtain input parameters (i.e kinetic parameters and reaction stoichiometry) that are then extrapolated, with additional thermo-physical properties and test conditions, to bench scale experiments like the cone calorimeter, gasification device or CAMLC $[22,23,24]$. However, in this case the intention was not to extrapolate the results to bench-scale tests on the metal acetates but to obtain information that could potentially be applied to the thermal decomposition and bench scale testing of EVA-MHs.

\subsubsection{Aluminium acetate}

The TGA experiments used to optimise the model were carried out in triplicate with a relative standard deviation (RSD) of less than $2 \%$. The mass loss and MLR data showed three distinct mass loss stages for the thermal decomposition of AIAc. However, inspection of FTIR data and analysis with ThermaKin modelling found that four reactions more suitably described the thermal decomposition of this sample. This demonstrates the applicability of pyrolysis modelling as a tool for extracting kinetic information and identifying thermal decomposition mechanisms that could otherwise be lost. Table 3 and Scheme 1 respectively show the kinetic parameters and stoichiometric reactions used to generate the simulated MLR curve in Figure 12. The simulation replicated the first MLR peak accurately, while the $T_{p}$ and peak MLR ( $p M L R$ ) of the second reaction showed good agreement despite the asymmetry of the peak, causing the prediction of the onset of this mass loss step to be slightly compromised (predicted MLR peaks based on a single set of Arrhenius parameters are always symmetrical). $T_{p}$ and PMLR of the third MLR peak were also well-predicted. The second, third and fourth reactions overlapped in the model, and changes to the parameters of any of these reactions affected the positioning and height of the peaks of all three overlapping stages. The set of kinetic and stoichiometric parameters in Table 3 best described the overall thermal decomposition. As mentioned previously, Ngohang [10] attributed the release of acetic acid before, and acetone after, EVA-ATH ignition to the lower activation energy of acetic acid release compared to acetone release. Witkowski [25] reported $E_{a}$ values of $1.69 \times 10^{5}$ and $3.45 \times 10^{5} \mathrm{~J} \mathrm{~mol}^{-1}$ for acetic acid and acetone release from EVA-ATH respectively, although it is important to note that acetic acid and acetone release from AIAC are much simpler reactions than the complex sequence of reactions resulting in EVA-ATH decomposition. Thus, acetic acid is generated via $\beta$-elimination chain-stripping from the polymer backbone, followed by diffusion, bubble formation and transport to escape from the polymer and 
alumina matrix. The acetic acid may also be trapped by the alumina and subsequently released, either as acetic acid or as acetone, $\mathrm{CO}_{2}$ and water. It must then escape from the molten decomposing polymer composite. The only comparable process here is acetone formation, where the acetate group is trapped by the metal oxide complex. The kinetic modelling performed found a reasonably similar activation energy value for the acetone-releasing reaction, suggesting that this may be the crucial ratedetermining step. However, it is important to note that the process reported by Witkowski is much more complex, including transport processes such as gas diffusion through the polymer matrix. The optimised model for AIAc had a maximum RSD of $12 \%$, with an average RSD value of $3 \%$. To validate the parameters that were optimised from the $10{ }^{\circ} \mathrm{C} \mathrm{min}^{-1} \mathrm{TGA}$ data, the simulations were run at 5 and $20^{\circ} \mathrm{C} \mathrm{min}^{-1}$ (Figure $13(\mathrm{a})$ and (b)).

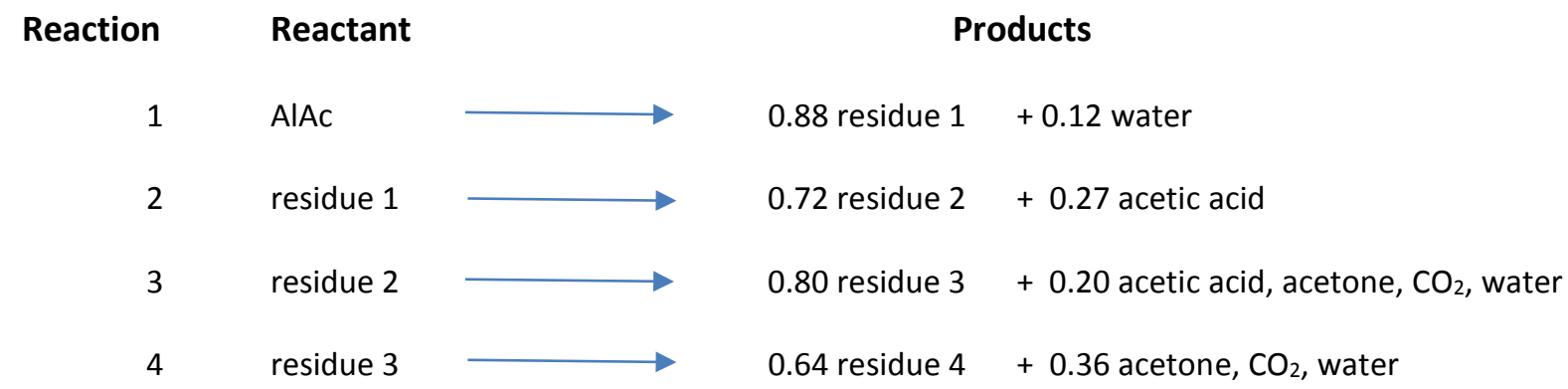

Scheme 1 Stoichiometric reactions describing the thermal decomposition of aluminium acetate

Table 3 Kinetic parameters obtained through modelling aluminium acetate pyrolysis at $10^{\circ} \mathrm{C} \mathrm{min}^{-1}$

\begin{tabular}{|c|c|c|c|}
\hline Reaction & $\mathrm{A} / \mathrm{s}^{-1}$ & $\mathrm{E}_{\mathrm{a}} / \mathrm{J} \mathrm{mol}{ }^{-1}$ & $\mathrm{~T}_{\mathrm{p}} /{ }^{\circ} \mathrm{C}$ \\
\hline 1 & $4.46 \times 10^{8}$ & $7.28 \times 10^{4}$ & 95 \\
\hline 2 & $1.89 \times 10^{11}$ & $1.40 \times 10^{5}$ & 286 \\
\hline 3 & $6.94 \times 10^{6}$ & $1.00 \times 10^{5}$ & 320 \\
\hline 4 & $7.47 \times 10^{2}$ & $6.50 \times 10^{4}$ & 364 \\
\hline
\end{tabular}

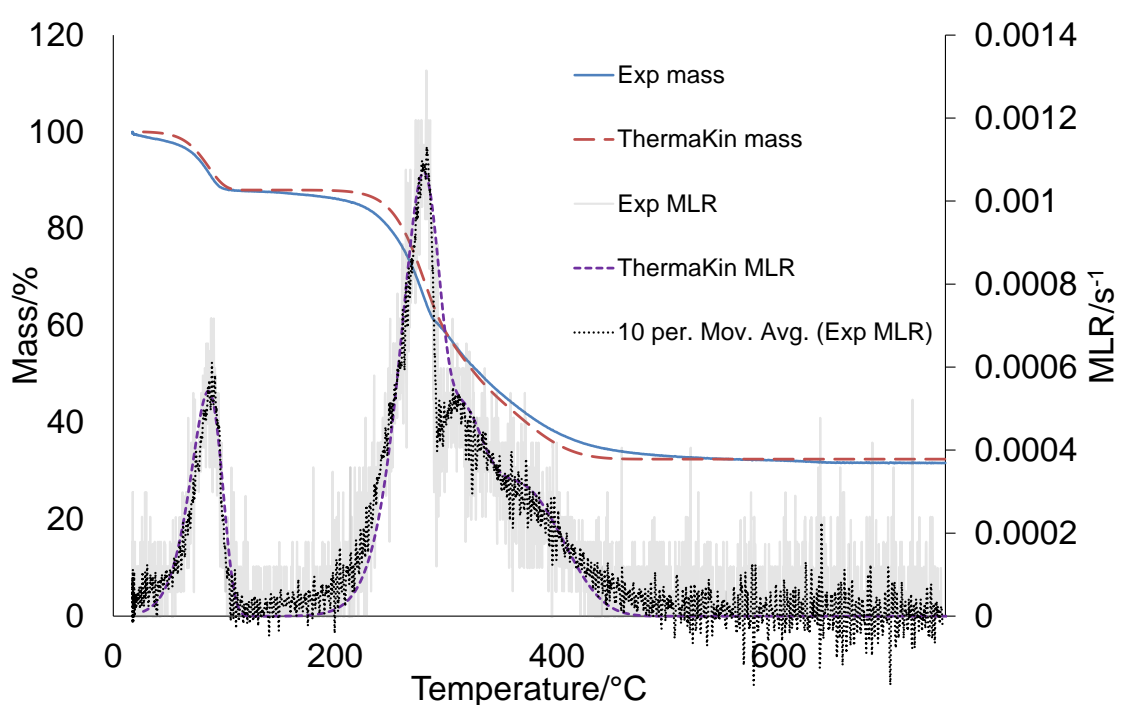

Figure 12 Experimental and simulated mass and mass loss rate curves for aluminium acetate heated at $10^{\circ} \mathrm{C} \mathrm{min}^{-1}$ in $\mathrm{N}_{2}$

(a) 


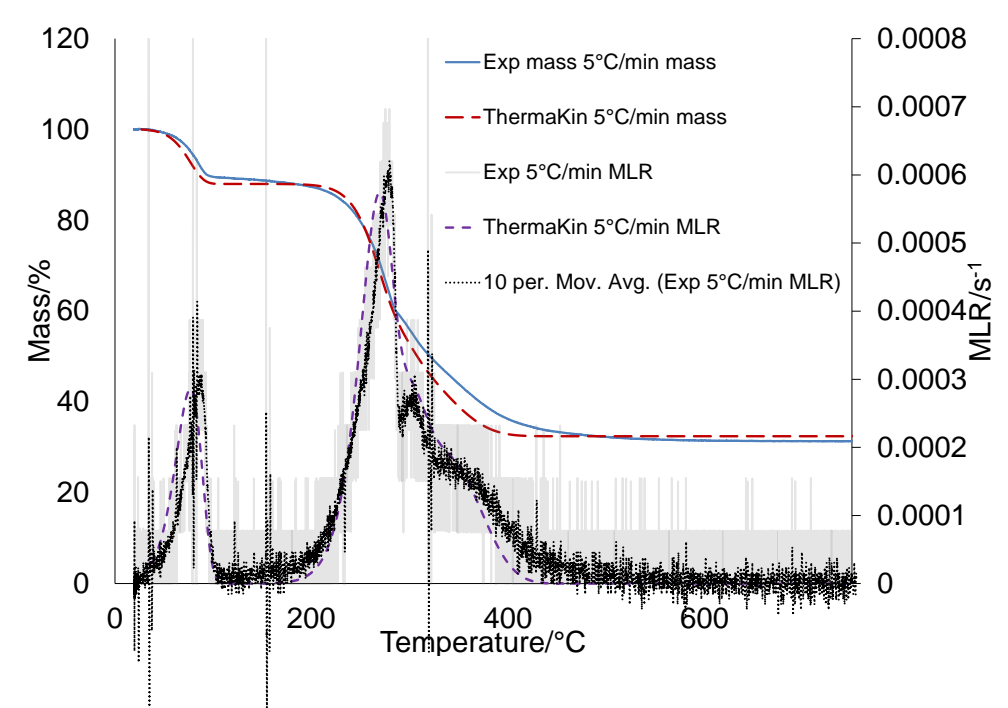

(b)

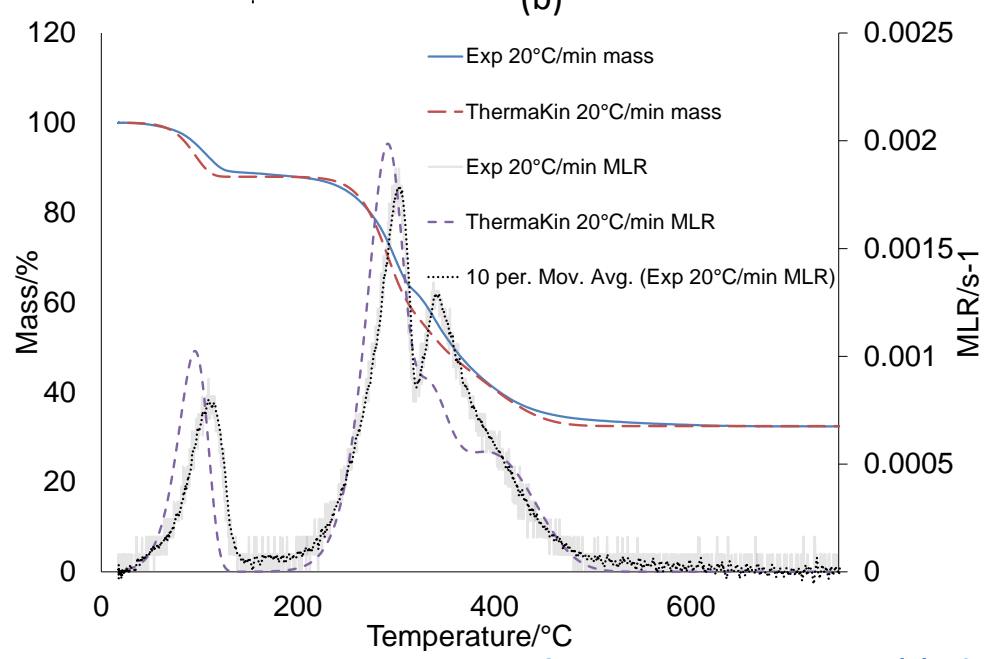

Figure 13 Experimental and simulated mass and MLR curves from aluminium acetate at (a) $5^{\circ} \mathrm{C} \mathrm{min}{ }^{-1}$ and (b) $20^{\circ} \mathrm{C} \mathrm{min}{ }^{-1}$

The simulation at $5{ }^{\circ} \mathrm{C} \mathrm{min}^{-1}$ captured the onset temperature and declining temperature of the first MLR peak, although $T_{p}$ was slightly underestimated. $T_{p}$ and $p M L R$ for the second simulated MLR peak were close to the experimental data and the onset of this peak was predicted well. The overlapping of reactions 3, 4 and 5 caused changes to the parameters of any one of these to affect the position and/or magnitude of the others. $T_{p}$ of the third simulated reaction was accurate and the pMLR value was acceptable. The PMLR for the fourth reaction was predicted well but the reaction ended in the simulation slightly earlier than in the experiment. Slower experimental heating rates increase the definition of mass loss steps and this is demonstrated here particularly by the enhanced separation of the fourth reaction compared to the result at $10{ }^{\circ} \mathrm{C} \mathrm{min}^{-1}$ (Figure 12). In Figure 12 it was not visually obvious that four reactions were required to describe the mass loss behaviour of AIAc; it was only through a combination of FTIR analysis and modelling that the necessity of a fourth reaction became clear. The overall mass loss and MLR traces of AIAc at $20{ }^{\circ} \mathrm{C} \mathrm{min}{ }^{-1}$ in $\mathrm{N}_{2}$ generally showed good agreement with the experiment, although there were some discrepancies: most notable are the simulation's over prediction of the height of the first and second MLR peaks, as well as the reduced separation between the second and third simulated peaks. The third and fourth simulated peaks were more separated than in the simulations of the $5{ }^{\circ} \mathrm{C} \mathrm{min}^{-1}$ and $10{ }^{\circ} \mathrm{C} \mathrm{min}{ }^{-1}$ data, possibly indicating experimental temperature gradients in the sample that could not be considered by the model. 
Validation at 5 and $20{ }^{\circ} \mathrm{C} \mathrm{min}-1$ has found that the kinetic parameters derived from the $10{ }^{\circ} \mathrm{C} \mathrm{min}^{-1}$ data (Table 3 ) were suitable for describing the pyrolysis of aluminium acetate.

\subsubsection{Magnesium acetate}

The RSD for the triplicate MgAc TGA results was less than $5 \%$. The MLR trace for MgAc shows four distinct mass loss steps. The simulation was created using the parameters in Table 4 and the reactions in Scheme 2, and shows close agreement with the experimental TGA data for MgAc in nitrogen at $10{ }^{\circ} \mathrm{C} \mathrm{min}^{-1}$ (Figure 14). The optimised kinetic parameters produced a model for MgAc that had a maximum RSD of $4 \%$, with an average RSD value of $1 \%$. The first MLR peak, corresponding to the loss of water, was most poorly simulated due to its asymmetry. The large particle size ( $1 \mathrm{~mm}$ diameter) of the MgAc contributed to this asymmetry presumably because thermal and species concentration gradients arose in the sample, resulting in accelerated decomposition of the outer region and delayed decomposition of the inner region [19]. This was tested by grinding the MgAc crystals to a fine powder and decomposing the powder under the same conditions as the crystals. Figure 15 compares TGA MLR results at $10{ }^{\circ} \mathrm{C} \mathrm{min}-1$ from $\mathrm{MgAc}$ in its crystalline form and after grinding to a fine powder. The water peak becomes sharper after grinding as product release is faster and more uniform, indicating a reduction in the particle size effect. However, it was felt that it was suitable to use one reaction to physically represent the loss of water from $\mathrm{MgAc}$, and using one reaction did not exceed the error limits applied for an acceptable fit.

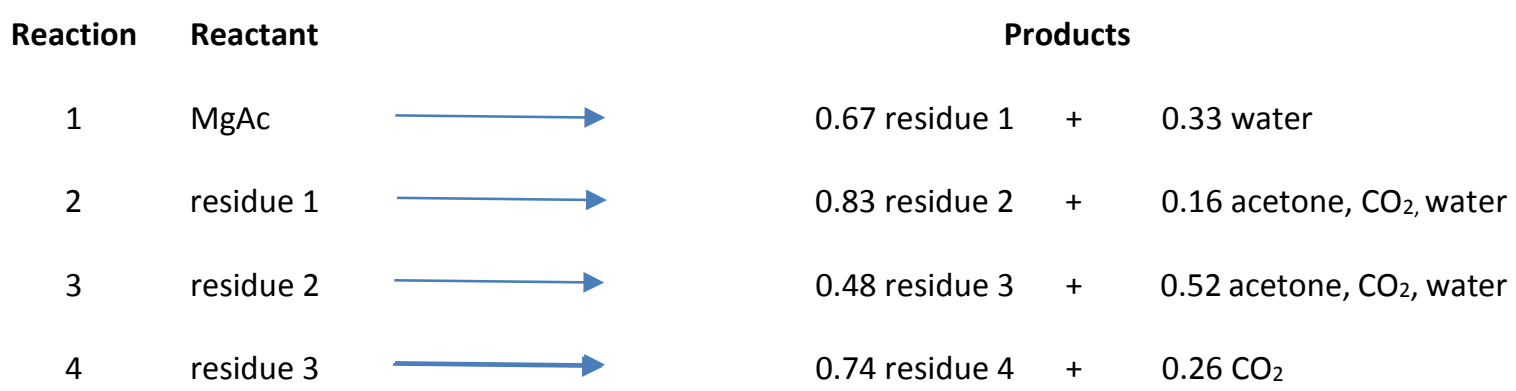

Scheme 2 Stoichiometric reactions describing the thermal decomposition of magnesium acetate

Table 4 Kinetic parameters obtained through modelling magnesium acetate pyrolysis at $10{ }^{\circ} \mathrm{C} \mathrm{min}{ }^{-1}$

\begin{tabular}{|c|c|c|c|}
\hline Reaction & $\mathrm{A} / \mathrm{s}^{-1}$ & $\mathrm{E}_{\mathrm{a}} / \mathrm{J} \mathrm{mol}^{-1}$ & $\mathrm{~T}_{\mathrm{p}} /{ }^{\circ} \mathrm{C}$ \\
\hline 1 & $3.88 \times 10^{5}$ & $5.50 \times 10^{4}$ & 93 \\
\hline 2 & $1.27 \times 10^{56}$ & $6.60 \times 10^{5}$ & 332 \\
\hline 3 & $9.48 \times 10^{25}$ & $3.33 \times 10^{5}$ & 361 \\
\hline 4 & $1.97 \times 10^{2}$ & $6.40 \times 10^{4}$ & 404 \\
\hline
\end{tabular}




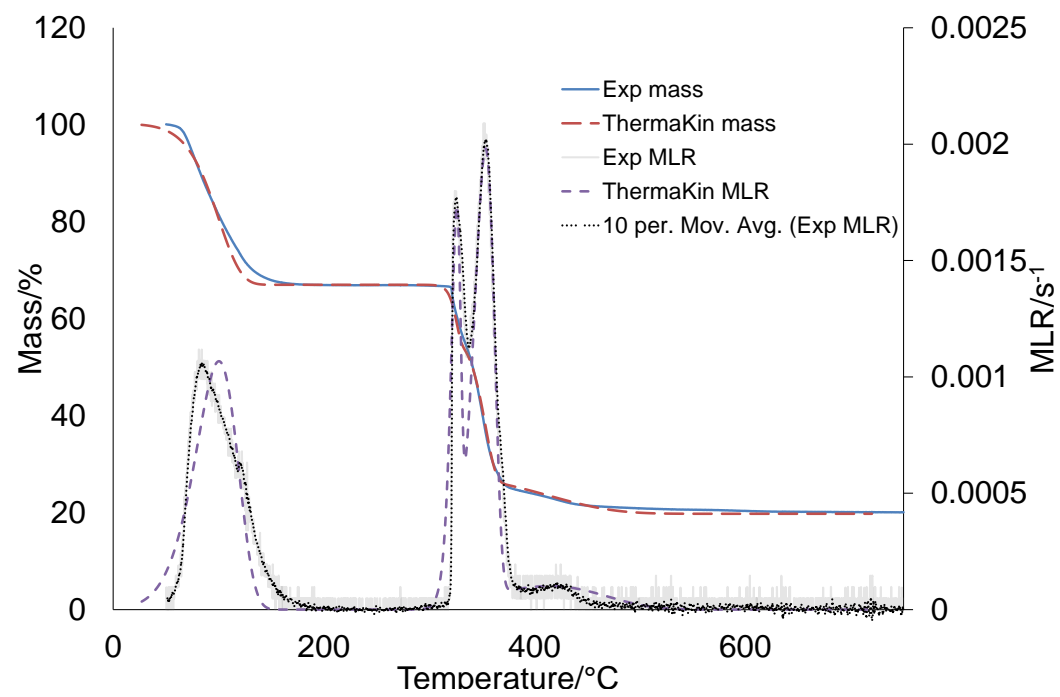

Figure 14 Experimental and simulated mass and mass loss rate curves for magnesium acetate heated at $10^{\circ} \mathrm{C} \min ^{-1}$ in $\mathrm{N}_{2}$

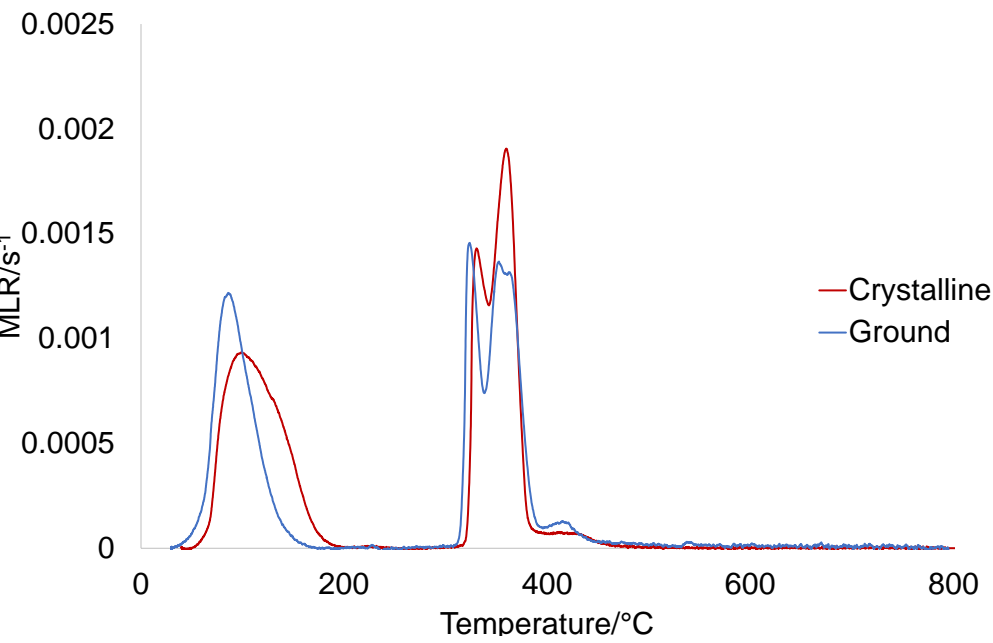

Figure 15 MLR comparison between crystalline and ground magnesium acetate heated at $10^{\circ} \mathrm{C} \mathrm{min}^{-1}$

The $5^{\circ} \mathrm{C} \mathrm{min}-1$ simulation predicted the experimental results well (Figure 16(a)). The slow heating rate reduced thermal and concentration gradients in the sample so the loss of water occurred as a sharper peak than in the $10{ }^{\circ} \mathrm{C} \mathrm{min}^{-1}$ data. Otherwise the simulation and experimental data agreed in terms of reaction onsets and $T_{p}$, although $p M L R$ for the second stage of acetone release was predicted as slightly too high. Comparing the experimental data at $20{ }^{\circ} \mathrm{C} \mathrm{min}{ }^{-1}$ to those generated at 5 and $10^{\circ} \mathrm{C} \mathrm{min}^{-1}$ finds that the peaks are more spread over a wider temperature range (Figure 16(b)). Increased heating rates tend to cause reactions to be more poorly defined than when samples are heated slower. High heating rates cause deviation from equilibrium and a temperature difference between the furnace (reported temperature) and the sample becomes more likely. Thus, reactions may appear to occur at temperatures greater than they actually do. At $20^{\circ} \mathrm{C} \mathrm{min}^{-1}$ the ThermaKin pMLR values are higher than the experimental values and peaks are more defined. ThermaKin assumes that components are at equilibrium so discrepancies between the model and experimental data may arise when experimental conditions caused deviation from equilibrium [26]. 


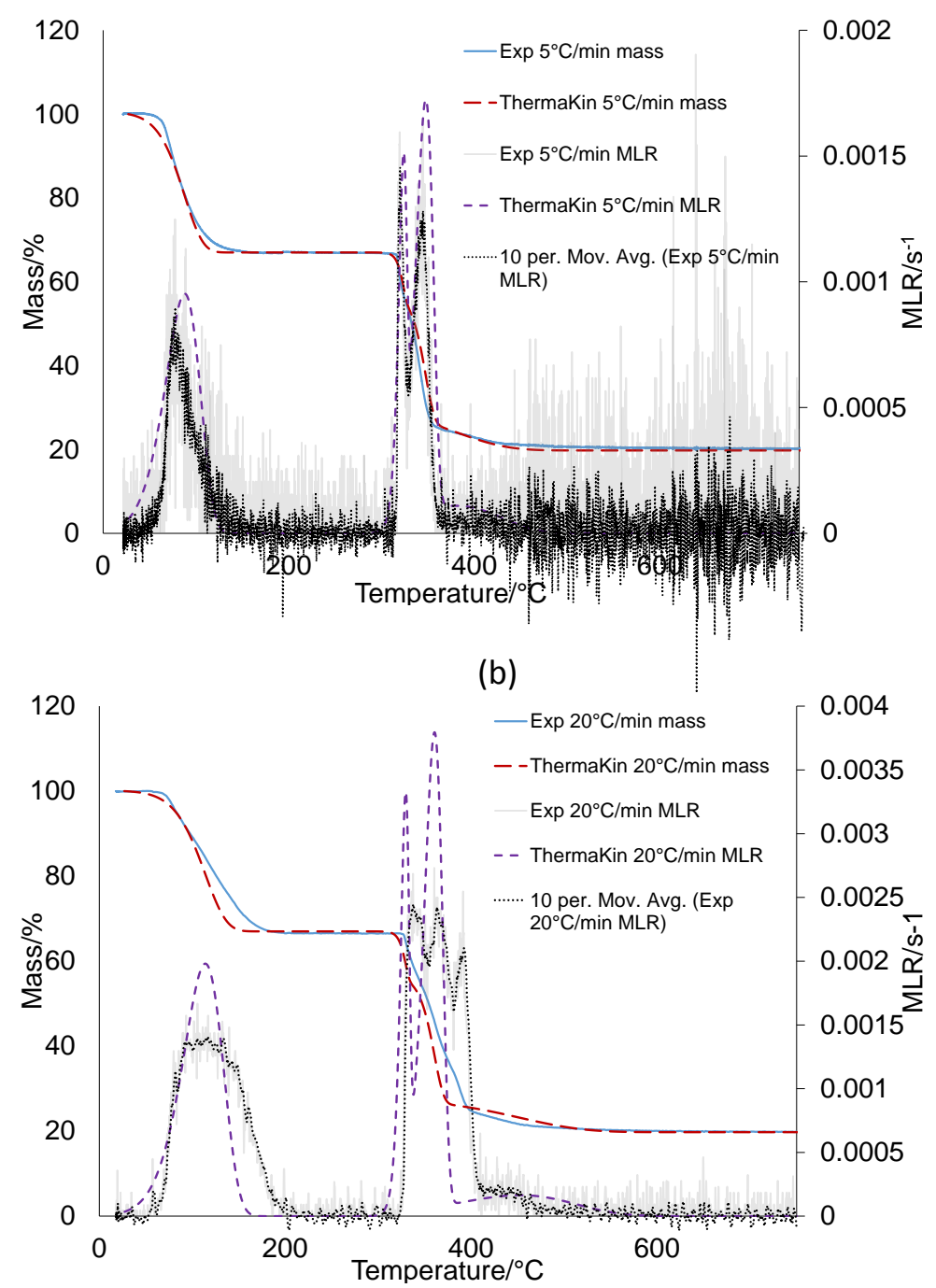

Figure 16 Experimental and simulated mass and MLR curves from magnesium acetate at (a) $5^{\circ} \mathrm{C} \mathrm{min}^{-1}$ and (b) $20^{\circ} \mathrm{C} \mathrm{min}-1$

\subsubsection{Calcium acetate}

The triplicate TGA analyses of CaAc generated an RSD of less than $4 \%$. The thermal decomposition of $\mathrm{CaAc}$ monohydrate at $10^{\circ} \mathrm{C} \mathrm{min}^{-1}$ in nitrogen showed five distinct mass loss steps (Figure 17). Gas phase FTIR analysis found that the first two were caused by the loss of water. Two reactions were accepted in the simulation to represent this, as the first mass loss was believed to be caused by loss of hygroscopic water, while the second mass loss was due to water released during the decomposition of the material. The optimised ThermaKin simulation (based on parameters from Table 5 and Scheme 3 ) closely resembled the mass loss and MLR of the first four steps, however, the final step $\left(\mathrm{CO}_{2}\right.$ release) produced an asymmetric MLR peak that was more poorly represented by the simulation. The optimised model for CaAc had a maximum RSD of $14 \%$, with an average RSD value of $1 \%$. Given that the error between the simulated and experimental data was within the limits (maximum RSD $=<15 \%$ and average $\mathrm{RSD}=<5 \%$ ) and that multiple reactions do not physically represent $\mathrm{CO}_{2}$ release, only one reaction was used in the simulation. Additonally, the loss of $\mathrm{CO}_{2}$ from $\mathrm{CaAc}$ is not thought to be important in prediction of flammability parameters, so time was not spent trying to perfect this fit. The prediction of the onset of mass loss for this step was slightly compromised in order to predict $T_{p}$. The experimental MLR peak for the final step sharply declined after its peak: the simulation cannot model this with one reaction. 


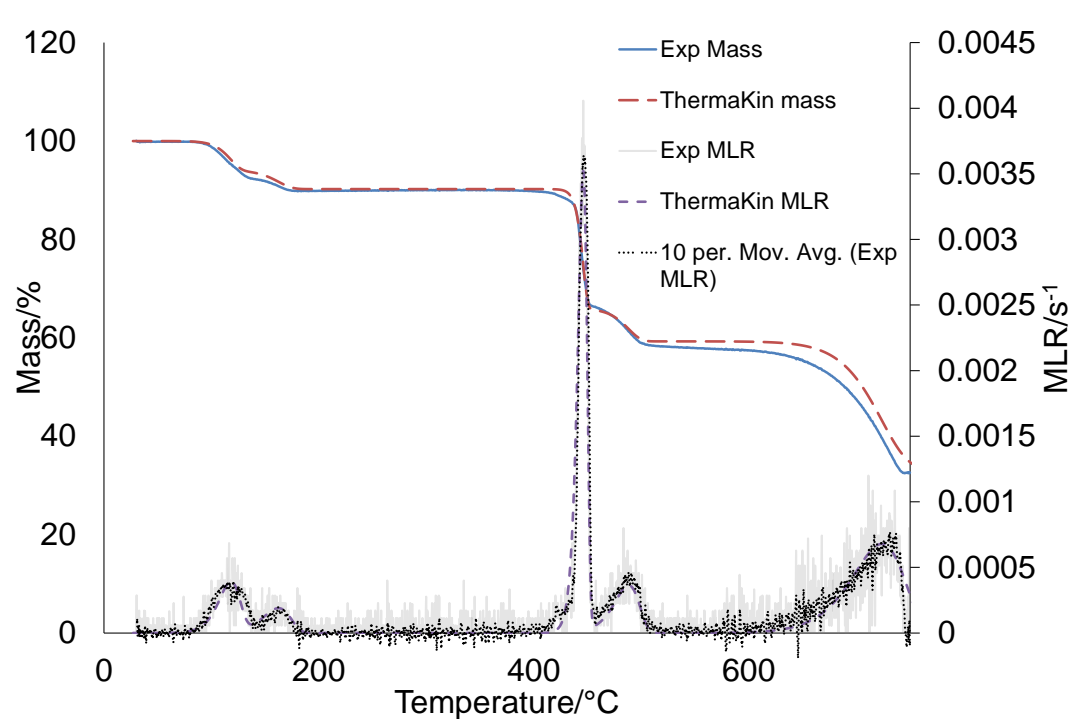

Figure 17 Experimental and simulated mass and mass loss rate curves for calcium acetate heated at $10^{\circ} \mathrm{C} \mathrm{min}^{-1}$ in $\mathrm{N}_{2}$

Reaction

1

2

3

4
Reactants

$\mathrm{CaAc}$

residue 1

residue 2

residue 3

residue 4

\section{Products}

0.94 residue $1+0.06$ water

0.96 residue $2+0.04$ water

0.73 residue $3+0.27$ acetone, $\mathrm{CO}_{2}$, water

0.90 residue $4+0.10$ acetone, $\mathrm{CO}_{2}, \mathrm{CO}$, water

0.56 residue $5+0.44 \mathrm{CO}_{2}$

Scheme 3 Stoichiometric reactions describing the thermal decomposition of calcium acetate.

Table 5 Kinetic and stoichiometric parameters obtained through modelling calcium acetate pyrolysis at $10^{\circ} \mathrm{C} \mathrm{min}-1$

\begin{tabular}{|c|c|c|c|}
\hline Reaction & $\mathrm{A} / \mathrm{s}^{-1}$ & $\mathrm{E}_{\mathrm{a}} / \mathrm{J} \mathrm{mol}{ }^{-1}$ & $\mathrm{~T}_{\mathrm{p}} /{ }^{\circ} \mathrm{C}$ \\
\hline 1 & $1.53 \times 10^{15}$ & $1.27 \times 10^{5}$ & 136 \\
\hline 2 & $3.10 \times 10^{12}$ & $1.20 \times 10^{5}$ & 182 \\
\hline 3 & $1.05 \times 10^{71}$ & $9.98 \times 10^{5}$ & 445 \\
\hline 4 & $4.04 \times 10^{26}$ & $4.15 \times 10^{5}$ & 501 \\
\hline 5 & $2.31 \times 10^{15}$ & $3.55 \times 10^{5}$ & 740 \\
\hline
\end{tabular}

The optimised model parameters predicted the experimental results from the thermal decomposition of CaAc in nitrogen, at both 5 and $20{ }^{\circ} \mathrm{C} \mathrm{min}^{-1}$, remarkably well (Figure 18). For the simulation at $5{ }^{\circ} \mathrm{C} \mathrm{min}{ }^{-1}$, the onset temperatures, pMLRs and $T_{p}$ of all reactions were predicted well. The simulated onset temperatures and $T_{p}$ values also showed reasonable agreement with experimental values for the $20^{\circ} \mathrm{C} \mathrm{min}-1$ data. $T_{p}$ for the final reaction was slightly too early in the simulation, but this resulted in better prediction of the overall mass loss curve for this step. The simulated pMLR values are acceptable for all reactions but reaction three, which was predicted as higher than in the experiment. The particle size of the CaAc sample was significantly smaller than in MgAc (fine powder) explaining the improved quality of the CaAc simulation's fit at the higher heating rate. 


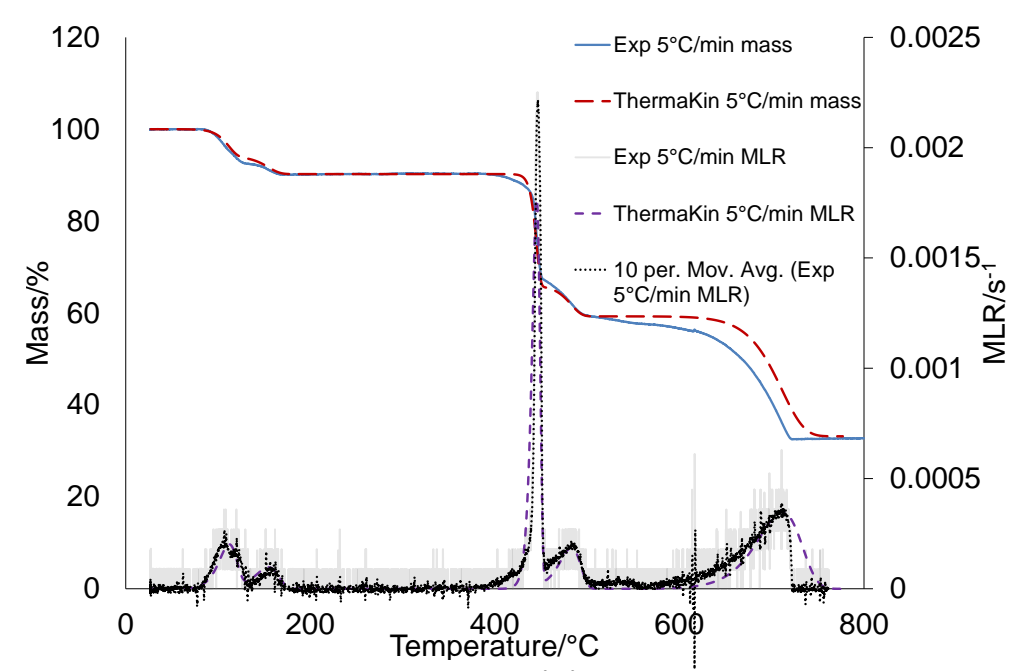

(b)

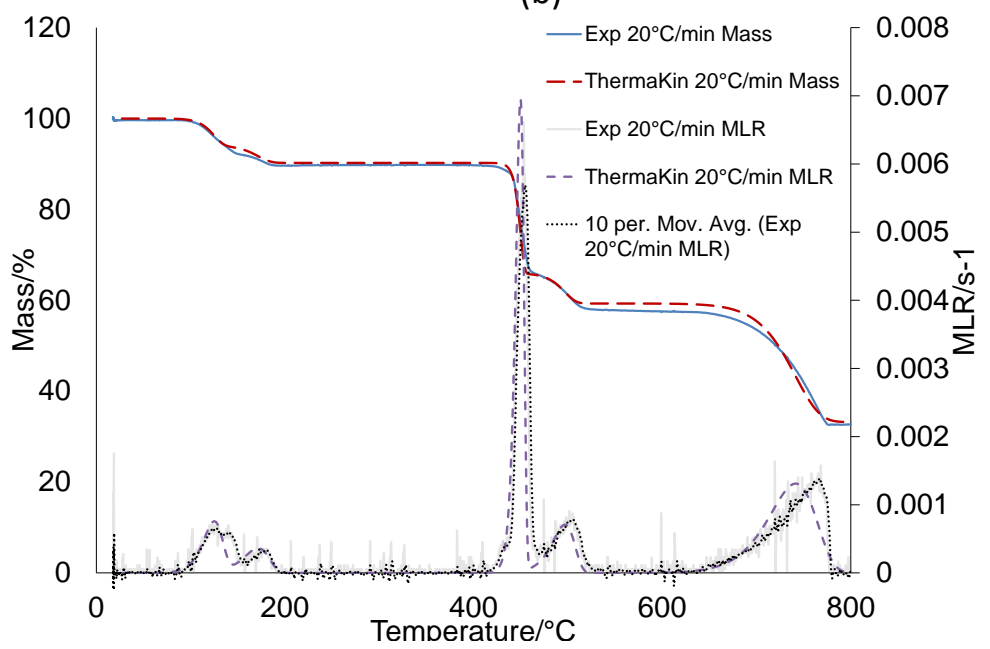

Figure 18 Experimental and simulated mass and MLR curves from calcium acetate at (a) $5^{\circ} \mathrm{C} \mathrm{min}^{-1}$ and (b) $20^{\circ} \mathrm{C} \mathrm{min}-1$

Another feature of Thermakin allows visualisation of the mass flux of gases out of the pyrolysing material as a function of temperature. This isolates the gases produced in each reaction and distinguishes overlapping peaks (otherwise the combined mass flux out peaks and the MLR trace are identical). Combining the TGA and ThermaKin data with the results from FTIR, where the pyrolysis gases were successfully identified, allows the ThermaKin results to adopt chemical significance that can be used to communicate the individual products of pyrolysis as a function of temperature. FTIR data can also complement ThermaKin, as assigning an identity to the gases involved in each reaction leads to more accurate definition of the components required for the input files, particularly in relation to burning behaviour. Figure 19 overlays the ThermaKin simulation of the mass flux out of the individual pyrolysis gases and the Gram-Schmidt (profile of total volatiles' release from the FTIR). It is important to note that the intensity of absorption in the infrared is a function of the polarity of the bond (more polar bonds absorb more strongly) and the concentration of the absorbing species. It is not, therefore, possible to state from the FTIR results that more acetic acid was released than acetone, particularly because acetone shows weaker absorption. 


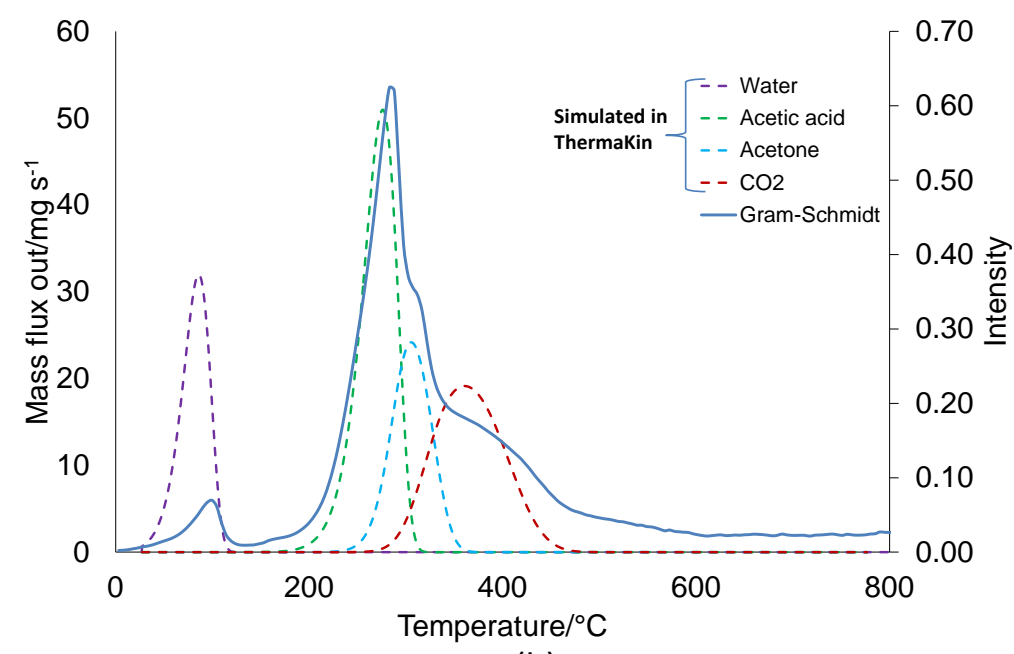

(b)

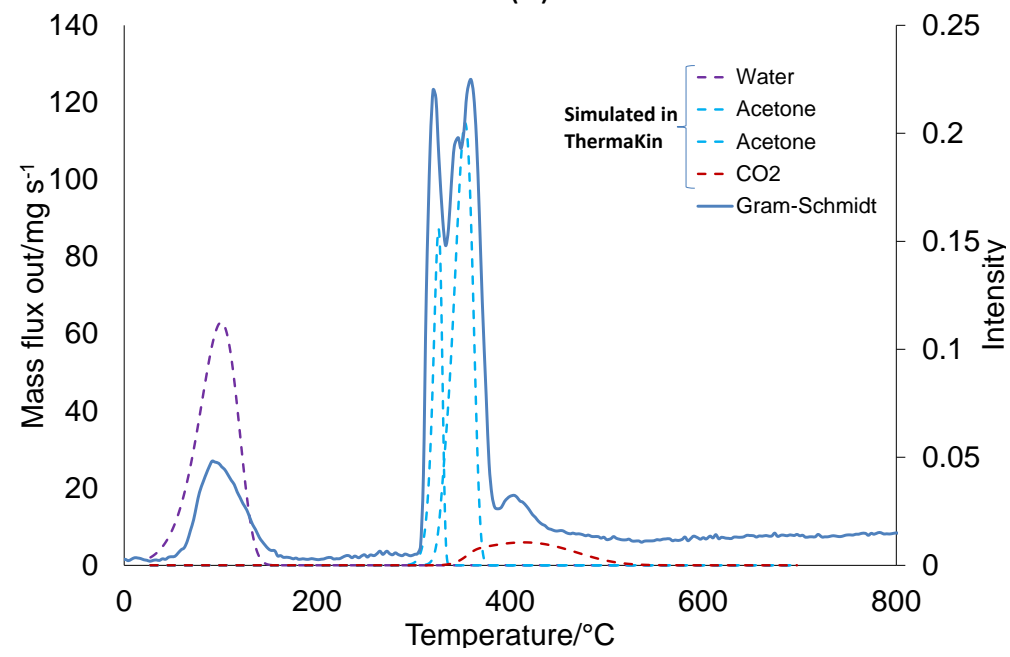

(c)

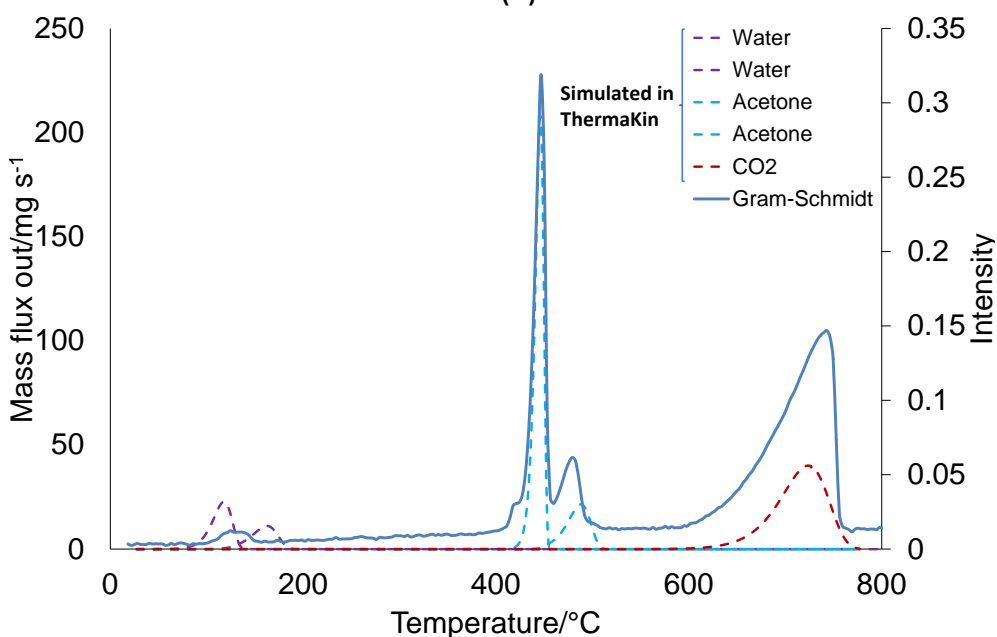

Figure 19 Overlay of the simulated mass flux of each gas out of the material and the total volatiles profile generated from the FTIR for (a) aluminium acetate, (b) magnesium acetate and (c) calcium acetate at $10^{\circ} \mathrm{C} \mathrm{min}^{-1}$ in $\mathrm{N}_{2}$

The purpose of the investigation into the thermal decomposition of the acetates was to use them as model compounds to deepen the understanding of EVA-MH decomposition in fires. The acetates provided relatively simple and clear decomposition data, but there are important differences between these model compounds and EVA-MH materials used in daily applications. First it is important to emphasise that decomposition products from the acetates were released almost immediately after formation; in EVA-MHs, volatile products may be trapped in the polymer matrix (with the possibility 
of recombination with the metal oxide) for some time before their diffusion to the atmosphere is complete. Therefore, decomposition temperatures for the same products would generally occur later in EVA-MHs compared to the corresponding metal acetates. The loss of water will also differ between metal acetates and the metal hydroxide in the filler, as for the metal acetates this depends on the hydration of the acetate molecules and their hygroscopicity, while the metal hydroxides have a fixed amount of water they can lose per molecule.

\subsubsection{Application of the model to EVA-ATH}

To demonstrate the use of the kinetic parameters extracted from the pyrolysis modelling of the acetate samples, TGA and microscale modelling was performed on EVA-ATH (Figure 20). Transport effects in the EVA-ATH were expected to be minimised, as it was tested as a fine powder. The MLR trace shows an intermediate mass loss between $330-380^{\circ} \mathrm{C}$. It is known that the first mass loss was caused by water from ATH dehydration and the largest MLR peak resulted from hydrocarbon release as a result of polyene decomposition. The intermediate mass loss falls within the temperature range of acetone detection from EVA-ATH $\left(360-420^{\circ} \mathrm{C}\right)$ reported by Witkowski et al [8]. It was assumed that this intermediate mass loss was acetone release and to test this, the $E_{a}$ value extracted from the pyrolysis modelling of AIAC at $10^{\circ} \mathrm{C} \mathrm{min}^{-1}$, for reaction 3 (acetone release) was input to reaction 2 of the EVA-ATH microscale model. The stoichiometric reactions and kinetic parameters used to generate the simulation for EVA-ATH are seen in Scheme 4 and Table 6 respectively. The $E_{a}$ value for acetone release from AIAc represents the intermediate mass loss step from EVA-ATH very well, and supports the postulated decomposition via the intermediate metal acetate complex.

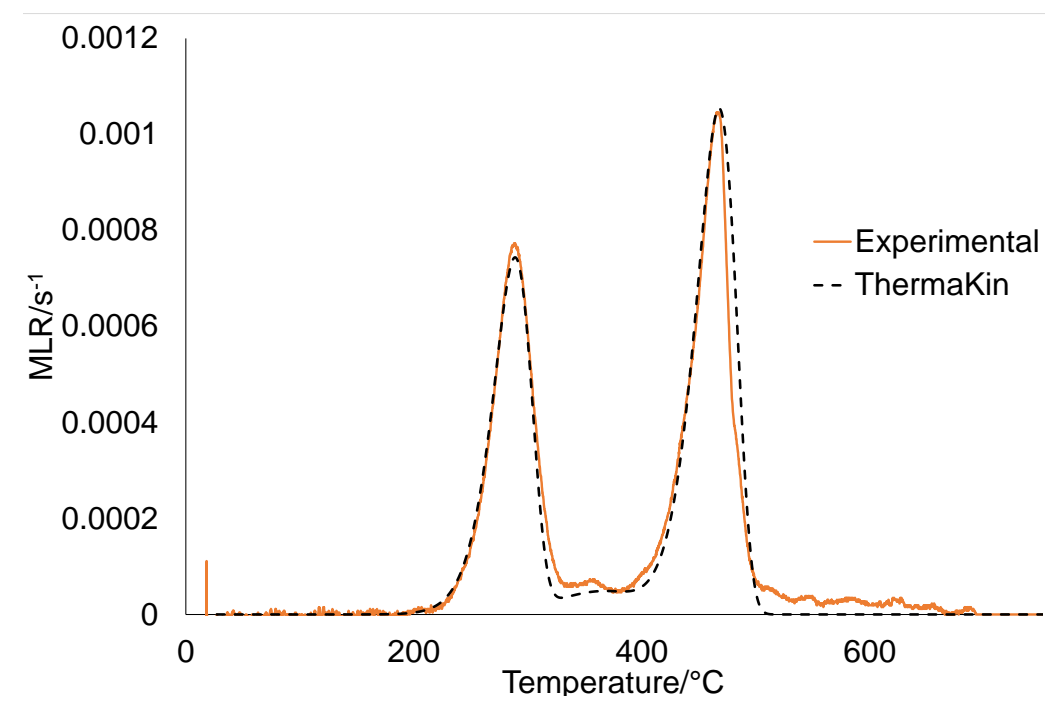

Figure 20 Experimental and simulated mass and MLR of EVA-ATH from TGA in $\mathrm{N}_{2}$ at $10^{\circ} \mathrm{C} \mathrm{min}^{-1}$

Scheme 4 Stoichiometric reactions describing the thermal decomposition of EVA-ATH.

Reaction

1

2

3

\section{Reactant}

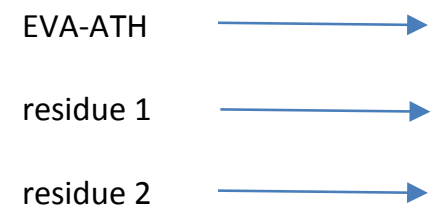

Products

0.80 residue $1+0.20$ water
0.97 residue $2+0.03$ acetone
0.64 residue $3+0.36$ hydrocarbons




\begin{tabular}{|c|c|c|c|}
\hline Reaction & $\mathrm{A} / \mathrm{s}^{-1}$ & $\mathrm{E}_{\mathrm{a}} / \mathrm{kJ} \mathrm{mol}^{-1}$ & $\mathrm{~T}_{\mathrm{p}} /{ }^{\circ} \mathrm{C}$ \\
\hline 1 & $2.52 \times 10^{12}$ & $1.55 \times 10^{5}$ & 287 \\
\hline $2^{*}$ & $4.16 \times 10^{7}$ & $1.00 \times 10^{5}$ & 362 \\
\hline 3 & $2.83 \times 10^{16}$ & $2.62 \times 10^{5}$ & 465 \\
\hline
\end{tabular}

* $E_{a}$ for reaction 2 was taken from the acetone-producing reaction (reaction 3 ) in AlAc.

\section{Conclusions}

TGA-FTIR analysis found that AIAc, MgAc and CaAc all decomposed to form the same products (acetone, water, $\mathrm{CO}_{2}$ ) as EVA-MHs investigated in other studies. This supports the hypothesis that intermediary metal acetate complexes are formed during the pyrolysis of EVA-MHs and are pivotal in the trapping and conversion of acetic acid to acetone. Efforts to understand the release of acetone and acetic acid have been hampered by the complexity of the system and the opacity of the inorganic/polymeric matrix to detailed chemical investigation. The use of 'model compounds' in the current work (AIAc, MgAc and $\mathrm{CaAc}$ ) provides the crucial information on the kinetics of the chemical transformation process from acetic acid to acetone, so that this ketonisation reaction can be isolated from the vapour transport (diffusion through the polymer) process. Applying this work to EVA-MH materials, there is evidence of a two-step process whereby acetic acid is either released directly from the polymer chain, by $\beta$-elimination to the vapour phase, or becomes trapped in the porous alumina or magnesia matrix until conversion to acetone occurs, whereupon it is released - this delay suppresses the initial sharp peak in the HRR curve. Pyrolysis modelling with ThermaKin successfully generated kinetic parameters that simulated the thermal decomposition of the metal acetates at multiple heating rates. ThermaKin was also useful for characterising individual mass loss stages that were otherwise obscured in the TGA data, and for separating the individual volatiles for each reaction. The novel approach of combining the FTIR data and the product gas peaks from ThermaKin helped identify individual volatiles and mixtures, and provided insight into the reaction mechanisms. The activation energy for the acetone-producing step from AIAc decomposition was input to a pyrolysis model for EVA-ATH and appropriately simulated the relevant portion of the MLR curve. This provides additional evidence that EVA-MHs decompose via an intermediate metal acetate complex and that this work on the model acetate compounds is relevant to the EVA-MH materials used in large volumes, especially for cable sheathing. Interesting future work could involve extrapolating the EVA-ATH model to the bench scale, with relevant thermo-physical data, to investigate whether the acetone-producing step contributes to the accuracy of larger scale predictions. Another area of future work could be to investigate the minimum $\mathrm{MH}$ loading that catalyses the ketonisation reaction, and whether the presence of other structures - such as nanoclays/nanoparticles, contributes to or inhibits the process. Manufacturers may strive to reduce $\mathrm{MH}$ loadings in EVA-MHs to improve physical and processing properties; this often involves replacement with nanomaterials, so such knowledge could assist in balancing these properties their with fire retardant behaviour.

\section{Acknowledgements}

The research leading to these results has received funding from the European Union's Seventh Framework Programme (FP7/2007-2013) under grant number 308391 as part of the DEROCA project. 


\section{References}

[1] Allen NS, Edge M, Rodriguez M, Liaux CM, Fontan E. Aspects of the thermal oxidation of ethylene vinyl acetate copolymer. Polymer Degradation and Stability 2000; 68: 363 - 371.

[2] Jin J, Chen S, Zhang J. UV aging behaviour of ethylene-vinyl acetate copolymers (EVA) with different vinyl acetate contents. Polymer Degradation and Stability 2010; 95: 725 - 732.

[3] Fernández Al, Hairie L, Formosa J, Chimenos JM, Antunes M, Velasco Jl. Characterization of poly(ethyleneco-vinyl acetate) (EVA) filled with low grade magnesium hydroxide. Polymer Degradation and Stability 2009; 94: $57-60$.

[4] Hollingbery LA, Hull TR. The fire retardant behaviour of huntite and hydromagnesite - A review. Polymer Degradation and Stability 2010; 95: $2213-2225$.

[5] Hull TR, Witkowski A, Hollingbery L. Fire retardant action of mineral fillers. Polymer Degradation and Stability 2011; 96: $1462-1469$.

[6] Laoutid F, Lorgouilloux M, Lesueur D, Bonnaud L, Dubois P. Calcium-based hydrated minerals: Promising halogen-free flame retardant and fire resistant additives for polyethylene and ethylene vinyl acetate copolymers. Polymer Degradation and Stability 2013; 98: 1617 - 1625.

[7] Chang M, Hwang S, Liu S. Flame retardancy and thermal stability of ethylene-vinyl acetate copolymer nanocomposites with alumina trihydrate and montmorillonite. Journal of Industrial and Engineering Chemistry 2014; 20: $1596-1601$.

[8] Witkowski A, Stec AA, Hull TR. The influence of metal hydroxide fire retardants and nanoclay on the thermal decomposition of EVA. Polymer Degradation and Stability 2010; 97: 2231 - 2240.

[9] Wang X, Rathore R, Songtipya P, Jimenez-Gasco M, Manias E, Wilke CA. EVA-layered double hydroxide (nano)composites: Mechanism of fire retardancy. Polymer Degradation and Stability 2011; 96: 301 - 313.

[10] Ngohang F, Fontaine G, Gay L, Bourbigot S. Smoke composition using MLC/FTIR/ELPI: Application to flame retarded ethylene vinyl acetate. Polymer Degradation and Stability 2015; doi:

10.1016/j.polymerdegradstab.2015.03.002.

[11] Hollingbery L. Decomposition and Fire Retardancy of Naturally Occurring Mixtures of Huntite and Hydromagnesite. [Ph. D thesis]. University of Central Lancashire; 2011.

[12] McGarry K, Zilberman J, Richard Hull T, David Woolley W. Decomposition and combustion of EVA and LDPE alone and when fire retarded with ATH. Polym Int. 2000;49:1193-1198

[13] Witkowski A, Hollingbery L, Hull TR. Fire retardancy of mineral fillers in EVA copolymers. ACS Symp Ser. 2012;1118:97-111

[14] Zilberman J, Hull TR, Price D, Milnes GJ, Keen F. Flame retardancy of some ethylene-vinyl acetate copolymer-based formulations. Fire Mater. 2000;24:159-164

[15] Stoliarov SI, Lyon RE. Thermo-Kinetic Model of Burning for Pyrolyzing Materials. Fire Safety Science 2008; 9: $1141-1152$.

[16] Lyon RE, Safronava N, Senese J, Stoliarov SI. Thermokinetic model of sample response in nonisothermal analysis. Thermochimica Acta 2012; 545: 82 - 89.

[17] Lyon RE, Safronava N and Oztekin E. A Simple Method for Determining Kinetic Parameters for Materials in Fire Models. Fire Safety Science - Proceedings of the Tenth International Symposium 2011; pp. $765-778$. 
[18] Li J and Stoliarov SI. Measurement of kinetics and thermodynamics of the thermal degradation for charring polymers. Polymer Degradation and Stability 2014; 106: 2 - 15.

[19] Haines, Peter, ed. RSC Paperbacks, Volume 29: Principles of Thermal Analysis and Calorimetry. Cambridge, GBR: Royal Society of Chemistry, 2002.

[20] Dudley Corporation, Calcium acetate monohydrate safety data sheet, Effective Date: January 1, 2015.

[21] Freudenheim ME. Acetone and lime. Journal of Physical Chemisty 1918; 22: 184 - 193.

[22] Linteris GT, Lyon RE, Stoliarov SI. Prediction of the gasification rate of thermoplastic polymers in fire-like environments. Fire Safety Journal 2013; 60: $14-24$.

[23] Stoliarov SI, Safronava N, Lyon RE. The effect of variation in polymer properties on the rate of burning. Fire and Materials 2009; 33: $257-271$.

[24] Witkowski A, Girardin B, Försth M, Hewitt F, Fontaine G, Duquesne S, Bourbigot S, Hull TR. Development of an anaerobic pyrolysis model for fire retardant cable sheathing materials. Polymer Degradation and Stability 2015; 113: $208-217$.

[25] Witkowski A. The use of numerical methods to interpret polymer decomposition data [Ph.D. thesis]. University of Central Lancashire; 2012.

[26] Stoliarov SI, Leventon IT, Lyon RE. Two-dimension Model of Burning for Pyrolyzable Solids. Federal Aviation Administration; 2013. Technical note DOT/FAA/TC-TN12/59. 